\title{
The Unexpected Impact of Parental Emotional Socialization on Theory of Mind and Emotion Regulation: The Case of Children with Intellectual Disabilities
}

\author{
Emilie Jacobs, Stéphanie Mazzone, Poline Simon, Nathalie Nader-Grosbois \\ Psychological Sciences Research Institute, UCLouvain, Louvain-la-Neuve, Belgium \\ Email:emilie.jacobs@uclouvain.be,nathalie.nader@uclouvain.be
}

How to cite this paper: Jacobs, E., Mazzone, S., Simon, P., \& Nader-Grosbois, N. (2019). The Unexpected Impact of Parental Emotional Socialization on Theory of Mind and Emotion Regulation: The Case of Children with Intellectual Disabilities. Psychology, 10, 1302-1332.

https://doi.org/10.4236/psych.2019.109084

Received: March 8, 2019

Accepted: July 20, 2019

Published: July 23, 2019

Copyright () 2019 by author(s) and Scientific Research Publishing Inc. This work is licensed under the Creative Commons Attribution International License (CC BY 4.0).

http://creativecommons.org/licenses/by/4.0/

\begin{abstract}
Improving our understanding of contribution of environmental factors to Theory of Mind (ToM) and Emotion Regulation (ER) competences in children with intellectual disabilities (IDs) is crucial to helping them to boost their emotional and social abilities. Parental emotion-related socialization behaviors (ERSBs) have been shown to be favorable factors for the development of these competences in preschoolers. However, few studies have investigated links between mothers' and fathers' ERSBs and socio-emotional abilities in children with IDs. The goal of this study is to explore the share of the variance in ToM and ER abilities explained by individual characteristic and each parent's reactions to the emotions of their children with IDs and emotion-related conversation. Twenty-seven mothers, 16 fathers, and their children with IDs participated. Direct and indirect measures of children's ToM were used. Questionnaires about children's ER competences and parents' ERSBs were completed by parents. The results demonstrated that, at preschool developmental age, parents' ERSBs had an impact on affective and cognitive ToM as well as on ER, depending on the parent's gender, on children's chronological and developmental age, and on the nature of ERSBs, namely reactions or conversations.
\end{abstract}

\section{Keywords}

Theory of Mind, Emotion Regulation, Parental Emotion-Related Socialization Behaviors, Intellectual Disabilities

\section{Introduction}

Socio-emotional competences, particularly ToM and ER, are keys to positive so- 
cial relationships and social inclusion for children with IDs. Improving our understanding of the development of ToM and ER, as well as of favorable factors for their development, could make effective intervention possible to boost their socio-emotional abilities. ToM refers to the ability to understand one's own and other people's mental states, including affective mental states such as emotions and desires, and cognitive ones such as intentions, beliefs, false beliefs, pretense, knowledge, thinking, visual perception and attention (Flavell, 1999). ER corresponds to abilities to monitor and modulate the intensity, valence, expression or frequency of emotions, in order to achieve goals in a socially adapted way (Eisenberg \& Spinrad, 2004; Thompson, 1994). Shields and Cicchetti (1997) define emotion dysregulation as mood lability and the inability to regulate negative emotions. According to the heuristic model of social competences for atypical children, developed by Yeates et al. (2007) and adapted by Nader-Grosbois (2011), the ToM skills have bidirectional links with social interactions including emotion regulation, and with social adjustment. What can we learn from the literature about ToM and ER in children with IDs?

\subsection{Theory of Mind and Emotion Regulation in Children with Intellectual Disabilities}

In comparison with typically developing children, children with IDs present either a deficit or a developmental delay in ToM in their affective and cognitive mental states. In their affective mental states, children with IDs display a delay in their understanding of causes and consequences of emotions (Baurain \& Nader-Grosbois, 2013b; Fiasse \& Nader-Grosbois, 2012; Garitte, 2003; Thirion-Marissiaux \& Nader-Grosbois, 2008c), compared to typically developing preschoolers of the same developmental age. In terms of their cognitive mental states, notably their understanding of beliefs, they have been found in different studies to present either a delay (Fiasse \& Nader-Grosbois, 2012; Giaouri, Alevriadou, \& Tsakiridou, 2010), or a deficit (Charman \& Campbell, 2002; Thirion-Marissiaux \& Nader-Grosbois, 2008c). This is due to the different tasks relating to beliefs and false beliefs used in these studies. Children with borderline IDs display difficulties in distancing themselves from their own perspective, and fail to differentiate their own knowledge from that of others (Baglio et al., 2016). Although evidence has been found for delays and deficits in ToM, the picture varies according to the matching criteria (e.g. children's developmental or chronological age) and above all to measures used which assess different mental states (cognitive and/or affective). Very few studies have used several tasks assessing various mental states, with both direct and indirect measures. The results obtained about the ToM profiles of children with IDs are therefore only fragmentary. To date, studies have focused only on some of the nine mental states described by Flavell (1999) and have not distinguished between affective and cognitive ToM abilities (Hutchins, Bonazinga, Prelock, \& Taylor, 2008).

Numerous studies of individuals with IDs have postulated either a developmental delay or deficits in emotion regulation at different ages and developmen- 
tal levels (Baurain \& Nader-Grosbois, 2012, 2013b; Nader-Grosbois, 2007). When children with IDs are matched for global developmental age with typically developing preschoolers, no difference is observed, supporting the hypothesis of developmental delay (Baurain \& Nader-Grosbois, 2013b). Regarding dysregulation, studies of children with IDs have reported more emotion dysregulation, in comparison with typically developing children (e.g. Baker, Fenning, Crnic, Baker, \& Blacher, 2007; Berkovits \& Baker, 2014). However, few studies have specifically examined both ER and emotion dysregulation in children with IDs, using an indirect measure like the Emotion Regulation Checklist (Shields \& Cicchetti, 1997), which collects parents' perception of this process observed in their children's daily lives. Delay and some specific features of ER have been identified, by means of observational research, concerning expression of basic emotions (joy, sadness, fear, anger), recognition of emotional facial expressions and emotional response modality (Baurain \& Nader-Grosbois, 2013a). Moreover, while some studies have underlined differences between syndromes (e.g. Down syndrome or Williams syndrome), many others have investigated ER in populations with developmental disabilities in the broadest sense of the term (Baurain \& Nader-Grosbois, 2013a).

The ToM and ER deficits revealed in children with IDs have been related to other weaknesses in cognitive and neuronal development (Cicchetti, Ackerman, \& Izard, 1995), language (Ricard, Cossette, \& Gouin Décarie, 1999; Whitman, 1990), executive functions (Danielsson, Henry, Messer, \& Rönnberg, 2012; Hippolyte, Iglesias, Van der Linden, \& Barisnikov, 2010), or even social interactions. The environment in which children grow up, especially their family, is key to the development of their socio-emotional competences (Guralnick, 1992, 1999). It is during parent-child interactions and through the socialization process that children acquire these specific competences (Hughes, 2011; Vygotsky, 1978), which underlines the importance of parents' ERSBs.

\subsection{Emotion-Related Socialization Behaviors in Parents of Children with Intellectual Disabilities}

Over the last two decades, several empirical studies have focused on parenting factors (e.g. Eisenberg, Cumberland, \& Spinrad, 1998; Fabes, Leonard, Kupanoff, \& Martin, 2001; Gottman, Katz, \& Hooven, 1996; Mazzone \& Nader-Grosbois, 2017c). These studies tested the provision of evidence-based intervention or training by professionals in order to improve the development of socio-emotional competences (e.g. Havighurst \& Harley, 2007; Jacobs \& Nader-Grosbois, In Preparation; Jacobs \& Nader-Grosbois, In Revision). However, few studies have examined mothers' and fathers' ERSBs toward their children with IDs.

In considering parental practices, it seems important to refer to the heuristic model of ERSBs designed by Eisenberg, Cumberland and Spinrad (1998). This distinguishes between different components, including reactions to children's emotions, parent-child emotion-related conversations and parents' emotional 
expressiveness. ERSBs have been studied essentially from a dichotomous viewpoint, dividing parental behaviors into two categories, supportive or unsupportive (Eisenberg et al., 1998; Eisenberg, Fabes, \& Murphy, 1996; Fabes, Poulin, Eisenberg, \& Madden-Derdich, 2002), and related to the valence of children's emotions. Parents can react to children's positive emotions with either supportive responses such as socialization and encouragement, or unsupportive responses such as reprimanding and discomfort. They can react to children's negative emotions either supportively, by giving comfort, offering a problem-focused response or encouraging emotions' expression, or unsupportively, by showing distress, punishing or minimizing the significance of the child's emotions.

Recent studies have shown that parents of children with IDs report more unsupportive reactions than parents of typically developing children (Jacobs, Mazzone, Simon, \& Nader-Grosbois, 2019; Rodas, Chavira, \& Baker, 2017; Rodas, Zeedyk, \& Baker, 2016). These results were obtained by means of self-reported measures. However, when an observational design and direct measure were used, the results were different. McIntyre (2008) observed that these parents displayed more negative interactions with their children with IDs during unstructured activities, whereas Rodas, Chavira and Baker (2017) did not observe any negative parenting during a naturalistic home observation. With regard to emotion-related conversations, Jacobs et al. (2019) found that mothers of children with IDs reported fewer conversations about emotions than mothers of typically developing preschoolers. Some authors have also noted a disparity between mothers and fathers of children with IDs. Rodas et al. noted that fathers reported more unsupportive reactions than mothers (2016), and that mothers reported more supportive reactions than fathers (2017).

While it is known that unsupportive parenting does not foster socio-emotional competences (e.g. Eisenberg et al., 1998; Eisenberg et al., 1996; Ruffman, Slade, \& Crowe, 2002), some researchers have reported that parents of children with IDs display fewer positive ERSBs. The link between ERSBs and socio-emotional competences such as ToM and ER needs to be investigated further in this population, using appropriate direct and indirect measures and taking the parents' and children's specific characteristics into account.

\subsection{Effects of Parenting on Emotion Regulation and Theory of Mind in Children with Intellectual Disabilities}

Parents' use of ERSBs has been shown to be vital for the development of ToM (e.g. Mazzone \& Nader-Grosbois, 2017c; O’Reilly \& Peterson, 2014; Pavarini, de Hollanda Souza, \& Hawk, 2013; Ruffman et al., 2002) and ER (e.g. Eisenberg et al., 1998; Gottman \& DeClaire, 1997; Perry, Calkins, Nelson, Leerkes, \& Marcovitch, 2012; Rogers, Halberstadt, Castro, MacCormack, \& Garrett-Peters, 2016) abilities in typically developing children. However, few studies have investigated the links or the effect of parents' ERSBs on the ToM and ER profiles of their children with IDs. 
To date, no studies have investigated the effect of ERSBs as reactions to children's emotions or emotion-related conversations in parents of children with non-specific IDs. The few studies investigating this relation focus on parents of children with Autistic Spectrum Disorder. With regard to parents' reactions, Mazzone and Nader-Grosbois (2017b) observed that mothers and fathers supported their children's understanding of affective (emotions and desires) and cognitive (thinking and beliefs) mental states. More precisely, the socialization and problem-focused reactions used by mothers and fathers fostered ToM abilities, notably the understanding of causes and consequences of emotions. Conversely, encouragement and comforting strategies were found to impede the development of ToM skills. With regard to conversations, Tingley, Gleason and Hooshyar (1994) noted that mothers of children with Down Syndrome reported fewer emotion-related conversations, but this result was not related to their children's emotional competences. In mothers of children with Autistic Spectrum Disorder, Slaughter, Peterson and Mackintosh (2007) found that narrative strategies of affect clarification were linked with ToM, whereas cognitive clarification had no effect on ToM development.

With regard to ER in children with developmental delays, maternal scaffolding has been identified as one of the factors predicting later social skills and as a protective factor against emotion dysregulation (Baker et al., 2007). Similarly, intrusive fathering has been related to children's emotion dysregulation and found to represent a risk factor for social skills development (Stevenson \& Crnic, 2013). In comparison with parents of typically developing children, parents of children with IDs express the same levels of negative and positive emotions (Green \& Baker, 2011; Wieland, Green, Ellingsen, \& Baker, 2014). However, mothers of children with IDs display less positive and more negative affect. Moreover, mothers' positive affect is not associated with social skills in their children with IDs. Parents' negative emotion expression is related to social skills in their children, but differently depending on the parents' gender (Green \& Baker, 2011).

Despite the numerous studies highlighting the crucial role of parents' ERSBs in ToM and ER development in typically developing children, much more investigation is needed in children with IDs. Internal factors such as impairments in executive functions, language or cognitive development have been extensively studied as harmful for emotional development, whereas environmental factors such as parents' ERSBs have been insufficiently taken into account in research into ToM or ER abilities in children with IDs.

\subsection{Objectives of the Present Study}

To address the gap in the literature concerning the contribution of ERSBs to the development of ToM and ER abilities in children with IDs, this study investigates specific relations between these variables in children with IDs, and examines the extent to which variability in the ToM and ER could be explained with reference to individual characteristics and different ERSBs. It was hoped 
that a better knowledge of these links could lead to the identification of more adapted and specific objectives for interventions with the parents of children with IDs.

\section{Method}

\subsection{Participants}

Twenty-seven mothers and 16 fathers of children with IDs were recruited in French-speaking Belgian schools and specialized schools for children with IDs. The directors, psychologists and teachers of these schools helped the researchers to identify children who met the inclusion criteria. The parents of these children were then informed about the research through a letter forwarded by the teachers. The parents were able to contact the researchers for further information and to give or withhold their consent. All the children had been diagnosed with non-specific intellectual disabilities according to AAIDD and DSM-V criteria, displaying limitations in intellectual functioning and in adaptive behavior and presenting an intellectual quotient between 50 and 70 . Children with Williams syndrome or Autistic Spectrum Disorder were excluded. The children were 20 boys and 7 girls with a preschool developmental age between. They had a mean global developmental age (GDA) of 59.26 months $(S D=16.24$, ranging from 38 to 88 months). Their mean chronological age was 103.15 months ( $S D=24.87$, ranging from 55 to 145 months).

The educational level of the parents was as follows: 1) $29.6 \%$ of mothers and $31.4 \%$ of fathers had not completed primary school; 2) $37.1 \%$ of mothers and $25 \%$ of fathers had completed primary school; 3) $14.8 \%$ of mothers and $6.2 \%$ of fathers had completed special elementary school; 4) $7.4 \%$ of mothers and none of the fathers had completed secondary school; 5) $7.4 \%$ of mothers and $12.5 \%$ of fathers had completed special secondary school; 6) none of the mothers and $18.7 \%$ of fathers had completed an apprenticeship; and 7) 3.7\% of mothers and $6.2 \%$ of fathers had completed a non-university higher education program.

\subsection{Procedure}

The ethical committee of UCLouvain approved the research before it was carried out. After being advised about the research conditions and giving their consent for participation through a form, the parents and their children with IDs took part in the study. Children were tested at school by experienced psychology researchers or by trained students in psychology. Parents completed questionnaires either at home or during an interview with the researcher. As some parents had difficulty in understanding some items, the researchers helped them to understand these items and complete the questionnaires in a face-to-face session.

\subsection{Measures}

Assessment of children through direct measures 
Wechsler Preschool and Primary Scales (WPPSI-III; Wechsler, 2004). This measure is used to assess the cognitive functioning and GDA of children. In a quiet room at school, we administered four subtests: "information", "vocabulary", "block design" and "matrix reasoning". These subtests were used only to ensure that children have a mild to moderate intellectual disabilities and a preschool GDA.

ToM-Emotions Tasks (Thirion-Marissiaux \& Nader-Grosbois, 2008b). The ToM-Emotions Tasks evaluate the understanding of causes and consequences of emotions, using a computer program. Three tasks are presented to the child. 1) A preliminary task of facial emotional expression recognition (joy, sadness, anger, and fear); 2) A second task evaluating the comprehension of causes of emotions. Stories are presented to the child, which has to predict the protagonist's emotion according to how the story ends. The child has to predict emotion (scores 1) and to give a response justification (if coherent scores 0.5 ). The maximum score is 6.3) The third task estimating the comprehension of the consequences of emotions. Four stories, each focusing on one of the four emotions, are presented to the child that has to infer the protagonist's behavior by choosing a response among three options (a socially adjusted, a maladjusted or a neutral behavior) and to justify his/her choice. The choice of the socially adjusted option scores 1 point, whereas the maladjusted or neutral options score 0 . A coherent justification scores 0.5 . The maximum score is 6 . The maximum total score is 12. Factor analysis revealed two subscales (causes and consequences) in the original version. Cronbach's alpha was 0.57 , and the test-retest stability was highly significant for the two subscales (between 0.56 and 0.68 ). The validation is good and the ToM-Emotions Tasks have been tested on typical and atypical child populations.

ToM-Beliefs Tasks (Thirion-Marissiaux \& Nader-Grosbois, 2008a). The ToM-Beliefs Tasks evaluate the understanding of beliefs through five tasks: 1) A deception skills task (Oswald \& Ollendick, 1989); 2) A change of representation task (Flavell, Everett, Croft, \& Flavell, 1981); 3) An appearance-reality task (Flavell, 1986); 4) An unexpected content task (Perner, Leekam, \& Wimmer, 1987); 5) A change of location task (Wimmer \& Perner, 1983). Each task scores 1 point, giving a total score of 5 . For the validation, the inter-judge agreement was very high (between 99\% and 100\%; Cohen's kappa between 0.98 and 0.99; Pearson correlation coefficient between 0.99 and 1). No difference between the test and retest session was obtained. The ToM-Beliefs Tasks were validated with children with intellectual disabilities.

ToM Task Battery-French version (Hutchins et al., 2008; Nader-Grosbois \& Houssa, 2016). This battery estimates children's ToM competences with regard to a range of different mental states. Nine tasks evaluate: 1) Emotion recognition; 2) Perspective taking; 3) Inference of desire-based emotion; 4) Inference of perception-based belief; 5) Inference of perception-based action; 6) False belief; 7) Inference of belief- and reality-based emotions and second order emotions; 8) Message-desire discrepancies; 9) Second-order false beliefs. Children 
are asked a number of different questions in each task: a control question, a test question and a prompt question. Each correct test question scores 1 point, for a total of 15 points. Concerning validation, the measure revealed good internal consistency $(\alpha=0.91)$.

Questionnaires completed by parents about the children

Emotion Regulation Checklist (ERC, Shields \& Cicchetti, 1997; ERC-vf, Nader-Grosbois \& Mazzone, 2015). This questionnaire assesses parents' perception of their children's emotional regulation. The 24 items concern behaviors corresponding to emotional response and reactions of joy, anger, empathy for peers and adults and behavior in situations of frustration and change of activity. This measure is applicable for children aged from 3 to 12 years old with or without a development disorder. Parents evaluate the frequency of the behavior on a 4-point Likert scale ranging from "never" to "almost always". Two raw scores can be obtained: an emotional regulation score and an emotional dysregulation score. The sum of the two raw scores gives a composite emotional regulation score. The different raw scores can be averaged. The factor analysis for the French version of this questionnaire highlights two factors, namely "emotional regulation" and “emotional dysregulation". Cronbach's alpha is 0.70 .

Questionnaires completed by parents about themselves

Theory of Mind Inventory-French-version (ToMI-vf, Hutchins, Prelock, \& Bonazinga, 2012; Houssa, Mazzone, \& Nader-Grosbois, 2014). This questionnaire assesses parents' perceptions of children's ToM abilities. Through 39 items, parents rate children's comprehension of nine mental states (namely emotions, beliefs, false belief, desires, intentions, attention, perception, thinking, pretense play), on a scale ranging from 0 to 20 . Three subscores are obtained, related to beliefs, socio-emotional mental states or thoughts. Validation of the French version matched that of the original version. Moreover, French version shows significant internal consistency $(\alpha=0.94)$ and test-retest reliability $(r=$ 0.86).

Parental Reactions toward Positive and Negative Emotions (Daffe \& Nader-Grosbois, 2009). This questionnaire is an integrated version of two questionnaires, namely Questionnaire sur les Réactions Parentales aux Emotions Positives Exprimées (QRPEPE, Ladouceur, Reid, \& Jacques, 2002) and Coping with Children's Negative Emotion Scale (CCNES, Fabes, Poulin, Eisenberg, \& Madden-Derdich, 2002; French version, Coutu, Debeau, Provost, Royer, \& Lavigueur, 2002). The questionnaire presents eight hypothetical scenarios in which a child feels negative (fear, sadness and anger) or positive emotions (joy). For the scenarios related to negative emotions, six parental reactions (encouragement of emotional expression, comforting, problem-focused responses, distress, minimizing and punitive response) are suggested, whereas for the positive scripts, four parental reactions (reprimand, discomfort, socialization and encouragement) are proposed. Parents indicate to what extent they use different strategies on a 7-point Likert scale ranging from "very unlikely" to "very likely". The factor analysis of this questionnaire, validated on 328 parents of TD children, hig- 
hlighted two subscales, supportive and unsupportive reactions for positive and negative emotions. Scores for supportive and unsupportive reactions and a score for each parental reaction can be obtained. Cronbach's alpha is 0.78 and 0.81 for negative scenarios and 0.77 and 0.62 for the joy scripts.

Questionnaire of Parent-Child Conversations about Emotions (QCPEE, Mazzone, Roskam, Mikolajczak, \& Nader-Grosbois, 2017). This questionnaire evaluates if parents-child emotion-related conversations are more supportive or unsupportive, based on a continuum. In the first part, parents have to classify according to their educational priorities five domains, namely intellectual, adaptive, affective, motor and social. They are also asked to what extent they agree or not with four preliminary statements about emotions (e.g. In general, I ask my child questions about his or her emotions (joy, sadness, fear, anger). The second part contains 24 items depicting supportive or unsupportive situation during parents-child emotion-related conversations. Parents indicate the frequency of the situation during the last two weeks on a 4-point scale ranging from "not at all" to " 5 or more times". However, if parents had not experienced the described situation, a "not applicable" response is also possible. In the third part, parents are asked to indicate which terms they use among a list of emotional terms. The factor analysis of this questionnaire, validated on 300 parents, identifies a single factor. Items depicting unsupportive strategies are therefore reversed. Cronbach's alpha is 0.91 .

\section{Results}

\subsection{Preliminary Analyses}

Table 1 describes the characteristics and competences in ToM and ER of the children. They were eight and a half years old and had a GDA of under 6 years. Concerning ToM competences, no difference was observed between competences in ToM related to emotions (ToM-Emotions) and to beliefs (ToM-Beliefs), using a paired sample $t$-test $(t=-0.01 ; n s)$. However, ANOVA on repeated measures demonstrated that there was a significant difference between the three scores of the ToM Task Battery, namely the affective, the cognitive and mixed scores $\left(F=55.39 ; p=0.000 ; \eta^{2}=0.73\right)$. Paired sample $t$-tests showed significant differences between affective and cognitive scores $(t=8.85 ; p=0.000 ; d=1.43)$; affective and mixed scores $(t=10.01 ; p=0.000 ; d=3.78)$; and cognitive and mixed scores $(t=3.87 ; p=0.001 ; d=1.71)$. Similarly, using ANOVA on repeated measures, we observed a significant difference between the three scores of the ToMi $\left(F=11.23 ; p=0.000 ; \eta^{2}=0.36\right)$. Paired sample $t$-tests revealed differences between socio-emotional and thoughts scores $(t=3.92 ; p=0.001 ; d=$ $0.88)$ and between belief and thoughts scores $(t=3.96 ; p=0.001 ; d=0.80)$. The score for thoughts was the lowest, implying that parents of these children perceived the most difficulties in the understanding of mental states such as intentions or knowledge. With a mean of $2.99(S D=0.39)$ out of a maximum score of 4 , the children seemed to have good ER abilities. Concerning dysregulation, with 
Table 1. Means and standard deviations of individual characteristics, theory of mind and emotion regulation competences of children with intellectual disabilities.

\begin{tabular}{|c|c|c|c|}
\hline & & $M$ & $S D$ \\
\hline \multicolumn{4}{|c|}{ Children's characteristics $(n=27)$} \\
\hline Gender (\% male) & & $71 \%$ & \\
\hline \multirow[t]{2}{*}{ Age (in months) } & Chronological age & 103.15 & 24.87 \\
\hline & Developmental age & 59.26 & 16.24 \\
\hline \multirow[t]{10}{*}{ Theory of Mind } & ToM Emotions ( $\max 12)$ & 7.43 & 3.13 \\
\hline & ToM Beliefs (max 5) & 2.78 & 1.44 \\
\hline & ToM Task Battery-Total (max 15) & 7.56 & 2.90 \\
\hline & ToM Task Battery-Affective (max 6) & 4.76 & 1.33 \\
\hline & ToM Task Battery-Cognitive $(\max 6)$ & 2.67 & 1.58 \\
\hline & ToM Task Battery-Mixed $(\max 3)$ & 0.48 & 0.89 \\
\hline & ToMi $(\max 20)$ & 13.31 & 3.13 \\
\hline & ToMi-Socioemotional $(\max 20)$ & 14.98 & 2.31 \\
\hline & ToMi-Beliefs $(\max 20)$ & 15.05 & 3.44 \\
\hline & ToMi-Thoughts $(\max 20)$ & 11.84 & 4.50 \\
\hline \multirow[t]{2}{*}{ Emotion Regulation } & Emotion Regulation (max 4) & 2.99 & 0.39 \\
\hline & Emotion Dysregulation $(\max 4)$ & 2.05 & 0.42 \\
\hline
\end{tabular}

a. Notes. $M=$ mean, $S D=$ standard deviation.

a mean score of 2.05 ( $S D=0.42$ ), the children appeared to have more difficulties in regulating negative emotions than positive emotions.

Table 2 presents parents' educational level characteristics and their ERSBs. Regarding their educational level, no difference appeared between mothers and fathers $\left(\chi^{2}=2.473 ; n s\right)$. An independent $t$-test revealed that there was no significant difference between mothers and fathers concerning ERSBs, in terms of reactions and conversations.

\subsection{Variability of Theory of Mind and Emotion Regulation Abilities in Children with Intellectual Disabilities according to Parents' Emotion-Related Behaviors}

In order to explore the extent to which parents' ERSBs (reactions and conversations) predicted the variance in the children's ToM and ER scores, linear regression analyses with a stepwise method were performed. Before doing this, we checked the inter-correlations between the children's competences in ToM and in ER and either individual characteristics (Table 3), or parents' ERSBs, independently for mothers and fathers (see Table 4 and Table 5). For the linear regression analyses, two separate models were presented, based on mothers' and fathers' emotion-related behaviors.

To investigate the impact of reactions, in Step 1 we entered children's characteristics (chronological and developmental age), as well as the level of education 
Table 2. Means and standard deviations of parents' characteristics.

\begin{tabular}{|c|c|c|}
\hline & $M$ & $(S D)$ \\
\hline \multicolumn{3}{|l|}{ Mothers' characteristics and ERSBs $(n=27)$} \\
\hline Educational level ( $\max 8)$ & 3.7 & $(2.75)$ \\
\hline \multicolumn{3}{|l|}{ Mothers' reactions } \\
\hline SUR_-E (max 7) & 5.23 & $(0.78)$ \\
\hline Comforting & 5.62 & $(0.81)$ \\
\hline Problem-focused & 5.54 & $(0.91)$ \\
\hline Encouragement of expression of emotion & 4.55 & $(1.11)$ \\
\hline NSUR_-E (max 7) & 3.88 & (1) \\
\hline Distress & 3.05 & $(1.32)$ \\
\hline Punitive & 3.50 & $(1.47)$ \\
\hline Minimizing responses & 5.12 & $(0.88)$ \\
\hline SUR_+E $(\max 7)$ & 5.09 & $(1.09)$ \\
\hline Socialization & 5.50 & $(1.62)$ \\
\hline Encouragement & 4.68 & $(1.52)$ \\
\hline NSUR_+E (max 7) & 3.54 & $(1.50)$ \\
\hline Reprimand & 4.22 & $(1.82)$ \\
\hline Discomfort & 2.88 & $(1.45)$ \\
\hline \multicolumn{3}{|l|}{ Mothers' conversations } \\
\hline QCPEE (max 4) & 2.16 & $(0.59)$ \\
\hline Joy-related terms & 5.73 & $(3.47)$ \\
\hline Anger-related terms & 2.91 & $(1.82)$ \\
\hline Sadness-related terms & 1.86 & $(1.24)$ \\
\hline Fear-related terms & 1 & $(1.60)$ \\
\hline Emotion-related verbs & 1.77 & $(1.69)$ \\
\hline \multicolumn{3}{|l|}{ Fathers' characteristics and ERSBs $(n=16)$} \\
\hline Educational level ( $\max 8)$ & 4.08 & $(3.31)$ \\
\hline \multicolumn{3}{|l|}{ Fathers' reactions } \\
\hline SUR_-E (max 7) & 5.39 & $(0.95)$ \\
\hline Comforting & 5.60 & $(0.86)$ \\
\hline Problem-focused & 5.74 & $(1.20)$ \\
\hline Encouragement of expression of emotion & 4.86 & $(1.14)$ \\
\hline NSUR_-E (max 7) & 3.83 & $(1.33)$ \\
\hline Distress & 3.39 & $(1.50)$ \\
\hline Punitive & 3.25 & (1.58) \\
\hline Minimizing responses & 4.84 & $(1.14)$ \\
\hline SUR_+E $(\max 7)$ & 5.39 & $(1.06)$ \\
\hline Socialization & 5.68 & $(1.43)$ \\
\hline encouragement & 5.09 & $(1.50)$ \\
\hline NSUR_+E (max 7$)$ & 3.75 & (1.48) \\
\hline Reprimand & 4.43 & (1.61) \\
\hline Discomfort & 3.06 & (2) \\
\hline \multicolumn{3}{|l|}{ Fathers' conversations } \\
\hline QCPEE (max 4) & 2.20 & $(0.82)$ \\
\hline Joy-related terms & 3.75 & $(4.71)$ \\
\hline Anger-related terms & 2.92 & (3.26) \\
\hline Sadness-related terms & 2.25 & $(2.83)$ \\
\hline Fear-related terms & 1.33 & (2.53) \\
\hline Emotion-related verbs & 1.17 & $(1.89)$ \\
\hline
\end{tabular}

a. Notes. $M=$ mean, $S D=$ standard deviation. 
Table 3. Spearman correlations between individual characteristics of parents and children with intellectual disabilities and the children's competences in theory of mind and emotion regulation.

\begin{tabular}{|c|c|c|c|c|c|c|c|c|c|c|c|c|c|c|c|}
\hline & 2 & 3 & 4 & 5 & 6 & 7 & 8 & 9 & 10 & 11 & 12 & 13 & 14 & 15 & 16 \\
\hline $\begin{array}{l}\text { 1) Mothers' } \\
\text { educational level }\end{array}$ & $10.679^{* *}$ & $-0.378^{\dagger}$ & $-0.371^{\dagger}$ & -0.217 & -0.180 & -0.191 & -0.056 & -0.135 & -0.242 & -0.406 & $-0.451^{\dagger}$ & -0.201 & $-0.479^{*}$ & 0.293 & 0.340 \\
\hline $\begin{array}{l}\text { 2) Fathers' } \\
\text { educational level }\end{array}$ & 1 & -0.170 & $-0.620^{* *}$ & -0.167 & -0.214 & -0.249 & -0.155 & -0.036 & -0.059 & -0.167 & -0.340 & -0.031 & -0.092 & 0.312 & 0.205 \\
\hline $\begin{array}{l}\text { 3) Children's } \\
\text { CA }\end{array}$ & & 1 & $0.469^{*}$ & $0.480^{*}$ & $0.508^{* *}$ & $0.530^{* *}$ & $0.515^{* *}$ & $0.547^{* *}$ & 0.298 & $0.455^{\dagger}$ & $0.525^{\star}$ & 0.285 & $0.478^{*}$ & 0.133 & $-0.565^{* *}$ \\
\hline $\begin{array}{l}\text { 4) Children's } \\
\text { GDA }\end{array}$ & & & 1 & $0.575^{* *}$ & $0.778^{* * *}$ & $0.768^{* * *}$ & $0.860^{* * *}$ & $0.492^{\star}$ & $0.591^{* *}$ & $0.602^{*}$ & $0.728^{* * *}$ & 0.272 & $0.459^{*}$ & 0.272 & -0.273 \\
\hline 5) ToM-Emotions & & & & 1 & $0.608^{\star *}$ & $0.589^{* *}$ & $0.604^{* *}$ & $0.572^{* *}$ & 0.309 & 0.328 & $0.556^{* *}$ & 0.265 & $0.514^{*}$ & 0.245 & $-0.534^{* *}$ \\
\hline 6) ToM-Beliefs & & & & & 1 & $0.697^{* * *}$ & $0.752^{* * *}$ & $0.624^{* *}$ & $0.439^{*}$ & $0.525^{*}$ & $0.735^{* * *}$ & 0.334 & $0.475^{*}$ & 0.325 & $-0.341^{\dagger}$ \\
\hline $\begin{array}{l}\text { 7) Total ToM } \\
\text { Task Battery }\end{array}$ & & & & & & 1 & $0.943^{* * *}$ & $0.904^{* * *}$ & $0.440^{*}$ & $0.602^{*}$ & $0.700^{* * *}$ & $0.393^{\dagger}$ & $0.481^{*}$ & 0.242 & 0.105 \\
\hline $\begin{array}{l}\text { 8) ToM Task } \\
\text { Battery-Affective }\end{array}$ & & & & & & & 1 & $0.786^{* * *}$ & $0.482^{\star}$ & $0.536^{*}$ & $0.722^{* * *}$ & 0.340 & $0.508^{*}$ & $0.411^{\dagger}$ & -0.282 \\
\hline $\begin{array}{l}\text { 9) ToM Task } \\
\text { Battery-Cognitive }\end{array}$ & & & & & & & & 1 & 0.200 & $0.557^{\star}$ & $0.675^{\star *}$ & $0.408^{\dagger}$ & $0.478^{*}$ & 0.161 & $-0.426^{*}$ \\
\hline $\begin{array}{l}\text { 10) ToM Task } \\
\text { Battery-Mixed }\end{array}$ & & & & & & & & & 1 & 0.199 & 0.250 & -0.073 & 0.039 & $0.527^{\star *}$ & -0.099 \\
\hline 11) ToMi & & & & & & & & & & 1 & $0.946^{* * *}$ & $0.630^{* *}$ & $0.618^{* *}$ & 0.040 & -0.322 \\
\hline $\begin{array}{l}\text { 12) ToMi- } \\
\text { Socioemotional }\end{array}$ & & & & & & & & & & & 1 & $0.618^{* *}$ & $0.621^{\star *}$ & 0.214 & $-0.501^{*}$ \\
\hline 13) ToMi-Beliefs & & & & & & & & & & & & 1 & $0.380^{\dagger}$ & 0.033 & -0.056 \\
\hline $\begin{array}{l}\text { 14) ToMi- } \\
\text { Thoughts }\end{array}$ & & & & & & & & & & & & & 1 & 0.020 & -0.249 \\
\hline $\begin{array}{l}\text { 15) Emotion } \\
\text { Regulation }\end{array}$ & & & & & & & & & & & & & & 1 & -0.169 \\
\hline $\begin{array}{l}\text { 16) Emotion } \\
\text { Dysregulation }\end{array}$ & & & & & & & & & & & & & & & 1 \\
\hline
\end{tabular}

a. Notes. $\mathrm{CA}=$ Chronological Age: GDA $=$ Global Developmental Age; ${ }^{*} p<0.05 ;{ }^{* *} p<0.01 ;{ }^{* * *} p<0.001 ;{ }^{\dagger} p<0.10$

of their mothers or fathers. Then, in Step 2, we entered the different supportive and unsupportive reactions to negative and positive emotions, namely comforting, problem-focused responses, encouragement of emotional expression, socialization, encouragement, distress, punitive reactions, minimizing, reprimand and discomfort. To explore the impact of emotion-related conversations, we entered the same variables in Step 1 and the total score of the QCPEE and the number of emotion-related verbs and terms that parents used with their children in Step 2. The variance inflation index (VIF) was used to assess multicollinearity. For each model, no multicollinearity was observed.

Links between mother' ERSBs, individual mothers' and children's characteristics, and ToM and ER profiles in children with IDs 
Table 4. Spearman correlations between the measures of mothers' emotion-related behaviors and socio-emotional skills of children with intellectual disabilities.

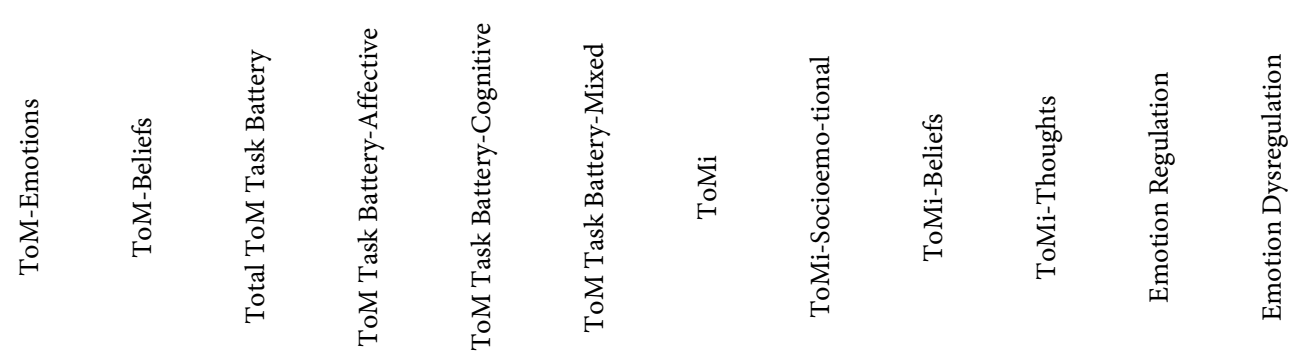

\begin{tabular}{|c|c|c|c|c|c|c|c|c|c|c|c|c|}
\hline \multicolumn{13}{|l|}{ Mothers' reactions } \\
\hline SUR_-E & -0.334 & $-0.394^{*}$ & -0.299 & -0.158 & -0.203 & -0.171 & -0.157 & -0.018 & -0.016 & -0.317 & 0.104 & $0.557^{\star *}$ \\
\hline Comforting & -0.290 & $-0.485^{*}$ & -0.370 & -0.368 & -0.362 & -0.047 & -0.178 & 0.037 & -0.193 & $-0.404^{\dagger}$ & -0.059 & $0.449^{*}$ \\
\hline Problem-focused & -0.175 & -0.321 & -0.084 & 0.094 & 0.023 & -0.091 & -0.122 & 0.119 & 0.176 & -0.150 & $0.360^{\dagger}$ & $0.437^{*}$ \\
\hline $\begin{array}{l}\text { Encouragement of } \\
\text { expression of emotion }\end{array}$ & -0.374 & -0.212 & -0.290 & -0.140 & -0.167 & -0.255 & -0.131 & -0.136 & -0.028 & -0.287 & 0.005 & $0.519^{* *}$ \\
\hline NSUR_-E & 0.201 & -0.150 & -0.023 & -0.102 & 0.152 & 0.125 & 0.203 & 0.011 & 0.005 & 0.168 & 0.220 & -0.278 \\
\hline Distress & 0.230 & 0.008 & 0.058 & 0.067 & 0.216 & 0.050 & 0.325 & 0.009 & 0.220 & 0.257 & 0.336 & -0.269 \\
\hline Punitive & 0.169 & -0.160 & -0.152 & -0.320 & -0.010 & 0.101 & 0.050 & 0.026 & -0.138 & 0.094 & -0.021 & -0.287 \\
\hline Minimizing responses & 0.070 & -0.250 & 0.109 & 0.076 & 0.221 & 0.172 & 0.121 & -0.019 & -0.036 & 0.047 & 0.282 & -0.032 \\
\hline SUR_+E & -0.057 & 0.026 & 0.092 & 0.205 & 0.141 & 0.066 & -0.011 & -0.104 & 0.057 & -0.116 & $0.385^{\dagger}$ & 0.203 \\
\hline Socialization & 0.191 & 0.131 & 0.253 & 0.351 & 0.287 & 0.095 & -0.027 & -0.265 & 0.016 & 0.094 & $0.532^{* *}$ & -0.175 \\
\hline Encouragement & -0.286 & -0.103 & -0.138 & -0.089 & -0.130 & -0.016 & 0.009 & 0.107 & 0.058 & -0.235 & -0.033 & $0.482^{*}$ \\
\hline NSUR_+E & $0.405^{\star}$ & 0.162 & 0.240 & 0.279 & 0.331 & 0.047 & 0.197 & -0.035 & 0.140 & 0.287 & $0.415^{*}$ & $-0.396^{*}$ \\
\hline Reprimand & $0.381^{*}$ & 0.206 & 0.311 & $0.403^{*}$ & 0.352 & 0.101 & 0.173 & 0.043 & 0.263 & 0.277 & $0.532^{* *}$ & -0.323 \\
\hline Discomfort & 0.350 & 0.066 & 0.093 & 0.054 & 0.228 & -0.039 & 0.180 & -0.132 & -0.047 & 0.219 & 0.172 & $-0.413^{*}$ \\
\hline $\begin{array}{l}\text { Emotion-related } \\
\text { conversations }\end{array}$ & -0.047 & 0.027 & -0.115 & 0.005 & 0.002 & -0.354 & 0.042 & 0.094 & 0.104 & -0.044 & -0.008 & -0.010 \\
\hline
\end{tabular}

a. Notes. SUR = supportive reactions; NSUR = unsupportive reactions; $-\mathrm{E}=$ negative emotion; $+\mathrm{E}=$ positive emotion; ${ }^{\star} p<0.05 ;{ }^{* *} p<0.01 ;{ }^{* * *} p<0.001 ;{ }^{\dagger} p$ $<0.10$.

Table 5. Spearman correlations between the measures of fathers' emotion-related behaviors and socio-emotional skills of children with intellectual disabilities.

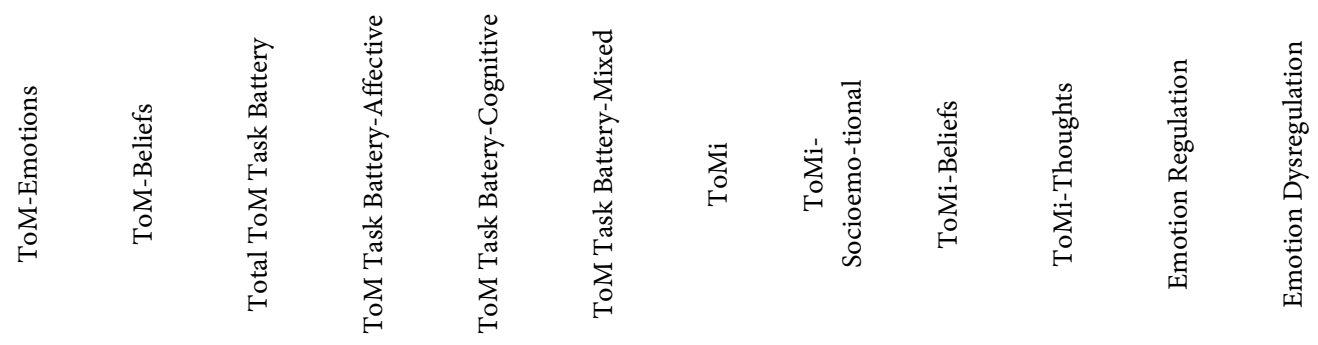

\begin{tabular}{cccccccccccccc}
\hline Mothers' reactions & & & & & & & & & & & & & \\
SUR_-E & $0.532^{*}$ & 0.040 & 0.148 & 0.049 & 0.009 & -0.082 & 0.491 & 0.287 & $0.485^{\dagger}$ & 0.366 & -0.108 & -0.257 \\
Comforting & $0.642^{* *}$ & 0.297 & 0.327 & 0.208 & 0.197 & 0.004 & $0.523^{\dagger}$ & $0.465^{\dagger}$ & $0.516^{*}$ & $0.482^{\dagger}$ & -0.080 & $-0.615^{*}$ \\
Problem-focused & $0.484^{\dagger}$ & 0.024 & 0.162 & 0.039 & 0.033 & 0.113 & 0.456 & 0.198 & $0.451^{\dagger}$ & 0.335 & 0.046 & -0.210 \\
\hline
\end{tabular}




\section{Continued}

\begin{tabular}{|c|c|c|c|c|c|c|c|c|c|c|c|c|}
\hline $\begin{array}{l}\text { Encouragement of } \\
\text { expression of emotion }\end{array}$ & 0.342 & -0.126 & -0.013 & -0.055 & -0.128 & -0.241 & 0.448 & 0.166 & 0.344 & 0.208 & -0.243 & 0.020 \\
\hline NSUR_-E & 0.398 & -0.128 & -0.133 & -0.255 & 0.189 & -0.024 & 0.151 & 0.219 & 0.073 & 0.204 & 0.065 & -0.378 \\
\hline Distress & 0.317 & -0.114 & -0.193 & -0.240 & 0.169 & -0.100 & 0.115 & 0.313 & 0.092 & 0.138 & 0.042 & -0.334 \\
\hline Punitive & $0.484^{\dagger}$ & -0.047 & -0.113 & -0.194 & 0.230 & -0.144 & 0.189 & 0.252 & 0.185 & 0.305 & 0.083 & $-0.509^{\dagger}$ \\
\hline Minimizing responses & 0.264 & -0.248 & -0.078 & -0.308 & 0.090 & 0.179 & 0.097 & 0.004 & -0.105 & 0.094 & 0.040 & -0.145 \\
\hline SUR_+E & 0.241 & -0.231 & 0.040 & -0.061 & -0.127 & 0.063 & 0.177 & -0.124 & 0.144 & 0.179 & 0.077 & 0.034 \\
\hline Socialization & 0.214 & -0.271 & -0.064 & -0.168 & -0.037 & -0.007 & -0.092 & -0.147 & -0.046 & 0.153 & 0.172 & -0.155 \\
\hline Encouragement & 0.137 & -0.069 & 0.118 & 0.070 & -0.144 & 0.096 & 0.385 & -0.041 & 0.252 & 0.114 & -0.050 & 0.195 \\
\hline NSUR_+E & 0.094 & -0.345 & -0.234 & -0.402 & 0.035 & -0.176 & -0.191 & 0.058 & -0.173 & -0.002 & 0.011 & -0.141 \\
\hline Reprimand & 0.346 & -0.200 & -0.045 & -0.308 & 0.105 & -0.112 & 0.063 & -0.027 & 0.062 & 0.218 & 0.046 & -0.305 \\
\hline Discomfort & -0.138 & -0.351 & -0.310 & -0.344 & -0.029 & -0.156 & -0.325 & 0.106 & -0.299 & -0.182 & -0.021 & -0.020 \\
\hline $\begin{array}{l}\text { Emotion-related } \\
\text { conversations }\end{array}$ & -0.087 & -0.180 & -0.126 & -0.225 & -0.013 & -0.541 & -0.078 & 0.260 & 0.025 & -0.045 & -0.142 & -0.166 \\
\hline
\end{tabular}

a. Notes. SUR = supportive reactions; NSUR = unsupportive reactions; $-\mathrm{E}=$ negative emotion; $+\mathrm{E}=$ positive emotion; ${ }^{*} p<0.05 ;{ }^{* \star} p<0.01 ;{ }^{* \star *} p<0.001 ;{ }^{\dagger} p$ $<0.10$.

Table 6 presents the results concerning significant predictors, including mothers' emotion-related reactions, of specific competences in ToM or ER profiles of children with IDs.

Concerning ToM competences, GDA explained 43\%, 57\% and 49\% respectively of the variance in the scores in ToM-Emotions, ToM-Beliefs and the ToM Task Battery. Looking at the subscores of the ToM Task Battery, we observed that the affective score was explained by a Model M2d including GDA ( $\beta=$ $0.885 ; p \leq 0.001)$ and mothers' educational level $(\beta=0.324 ; p<0.05)$. Likewise, a Model M2f including GDA $(\beta=0.640 ; p<0.01)$ and punitive reactions to negative emotions $(\beta=0.489 ; p<0.05)$ explained $41 \%$ of the variance of the mixed mental states score. For the cognitive score, chronological age $(\beta=0.487 ; p<$ 0.05 ) explained $19 \%$ of the variance. Chronological age also explained $47 \%$ of the variance in parents' perceptions of their children's ToM skills (measured by ToMi). A Model M2h including chronological age $(\beta=0.448 ; p<0.05)$ and GDA $(\beta=0.427 ; p<0.05)$ explained $55 \%$ of the variance of the sub-score of the ToMi related to thoughts, whereas Model M4i including chronological age ( $\beta=$ $0.922 ; p=0.000)$, problem-focused reactions $(\beta=0.663 ; p=0.000)$, minimization $(\beta=-0.629 ; p=0.000)$ and distress $(\beta=0.254 ; p<0.05)$ explained $85 \%$ of the variance in ToMi-Beliefs subscore. Regarding ER, reprimand reactions $(\beta=0.514$; $p<0.05)$ explained $23 \%$ of the variance in parents' perceptions of their children's ER competences, while $30 \%$ of the variance in emotion dysregulation was explained by chronological age $(\beta=-0.576 ; p<0.01)$.

Table 7 presents the results concerning significant predictors, including mothers' emotion-related conversations, of competences in ToM or ER of children with IDs. 
Table 6. Predictors of socio-emotional skills of children with intellectual disabilities, including mothers' reactions.

\begin{tabular}{|c|c|c|c|c|c|}
\hline \multicolumn{6}{|c|}{ Mothers' Model } \\
\hline \multirow[b]{2}{*}{ Predictors } & \multicolumn{5}{|c|}{ ToM-Emotions } \\
\hline & B & $\mathrm{SE} / \mathrm{B}$ & $\beta$ & $\mathrm{R}^{2}$ adj & $\mathrm{F}$ \\
\hline Model M1a & & & & 0.430 & $17.591^{\star *}$ \\
\hline \multirow[t]{2}{*}{ GDA } & 0.153 & 0.036 & $0.675^{\star *}$ & & \\
\hline & \multicolumn{5}{|c|}{ ToM-Beliefs } \\
\hline Predictors & B & $\mathrm{SE} / \mathrm{B}$ & $\beta$ & $\mathrm{R}^{2}$ adj & $\mathrm{F}$ \\
\hline Model M1b & & & & 0.570 & $30.170^{* * *}$ \\
\hline \multirow[t]{2}{*}{ GDA } & 0.075 & 0.014 & $0.768^{* * *}$ & & \\
\hline & \multicolumn{5}{|c|}{ ToM Task Battery-Total } \\
\hline Predictors & B & $\mathrm{SE} / \mathrm{B}$ & $\beta$ & $\mathrm{R}^{2}$ adj & $\mathrm{F}$ \\
\hline Model M1c & & & & 0.496 & $22.671^{* * *}$ \\
\hline \multirow[t]{2}{*}{ GDA } & 0.129 & 0.027 & $0.721^{* * *}$ & & \\
\hline & \multicolumn{5}{|c|}{ ToM Task Battery-Affective } \\
\hline Predictors & B & $\mathrm{SE} / \mathrm{B}$ & $\beta$ & $\mathrm{R}^{2}$ adj & $\mathrm{F}$ \\
\hline Model M1d & & & & 0.638 & $36.274^{* * *}$ \\
\hline GDA & 0.077 & 0.013 & $0.810^{* * *}$ & & \\
\hline Model M2d & & & & 0.729 & $27.835^{\star * *}$ \\
\hline GDA & 0.084 & 0.011 & $0.885^{\star * *}$ & & \\
\hline \multirow[t]{2}{*}{ SES } & 0.168 & 0.062 & $0.324^{*}$ & & \\
\hline & \multicolumn{5}{|c|}{ ToM Task Battery-Cognitive } \\
\hline Predictors & B & $\mathrm{SE} / \mathrm{B}$ & $\beta$ & $\mathrm{R}^{2}$ adj & $\mathrm{F}$ \\
\hline Model M1e & & & & 0.197 & $5.894^{\star}$ \\
\hline \multirow[t]{2}{*}{$\mathrm{CA}$} & 0.033 & 0.013 & $0.487^{*}$ & & \\
\hline & \multicolumn{5}{|c|}{ ToM Task Battery-Mixed } \\
\hline Predictors & B & $\mathrm{SE} / \mathrm{B}$ & $\beta$ & $\mathrm{R}^{2}$ adj & $\mathrm{F}$ \\
\hline Model M1f & & & & 0.208 & $5.994^{*}$ \\
\hline GDA & 0.025 & 0.010 & $0.500^{*}$ & & \\
\hline Model M2f & & & & 0.406 & $7.504^{* *}$ \\
\hline GDA & 0.032 & 0.009 & $0.640^{\star *}$ & & \\
\hline \multirow[t]{2}{*}{ Punishment_-E } & 0.261 & 0.099 & $0.489^{*}$ & & \\
\hline & \multicolumn{5}{|c|}{ ToMi-Total } \\
\hline Predictors & B & $\mathrm{SE} / \mathrm{B}$ & $\beta$ & $\mathrm{R}^{2}$ adj & $\mathrm{F}$ \\
\hline
\end{tabular}


E. Jacobs et al.

\section{Continued}

\begin{tabular}{|c|c|c|c|c|c|}
\hline Model M1g & & & & 0.473 & $12.661^{\star \star}$ \\
\hline \multirow[t]{2}{*}{$\mathrm{CA}$} & 0.086 & 0.024 & $0.717^{* *}$ & & \\
\hline & \multicolumn{5}{|c|}{ ToMi-Thoughts } \\
\hline Predictors & B & $\mathrm{SE} / \mathrm{B}$ & $\beta$ & $\mathrm{R}^{2}$ adj & $\mathrm{F}$ \\
\hline Model M1h & & & & 0.451 & $14.995^{\star * *}$ \\
\hline $\mathrm{CA}$ & 0.114 & 0.029 & $0.695^{\star * *}$ & & \\
\hline Model M2h & & & & 0.552 & $11.478^{* * * *}$ \\
\hline CA & 0.073 & 0.032 & $0.448^{*}$ & & \\
\hline \multirow[t]{2}{*}{ GDA } & 0.109 & 0.051 & $0.427^{\star}$ & & \\
\hline & \multicolumn{5}{|c|}{ ToMi-Beliefs } \\
\hline Predictors & B & $\mathrm{SE} / \mathrm{B}$ & $\beta$ & $\mathrm{R}^{2}$ adj & $\mathrm{F}$ \\
\hline Model M1i & & & & 0.495 & $17.680^{\star * *}$ \\
\hline CA & 0.115 & 0.027 & $0.725^{* * *}$ & & \\
\hline Model M2i & & & & 0.617 & $14.684^{* * * *}$ \\
\hline CA & 0.129 & 0.025 & $0.815^{\star * * *}$ & & \\
\hline Problem Focused_-E & 1.869 & 0.758 & $0.381^{*}$ & & \\
\hline Model M3i & & & & 0.800 & $23.630^{* * * *}$ \\
\hline CA & 0.150 & 0.019 & $0.944^{* * * *}$ & & \\
\hline Problem Focused_-E & 3.203 & 0.649 & $0.653^{* * * *}$ & & \\
\hline Minimization_-E & -2.289 & 0.597 & $-0.497^{\star *}$ & & \\
\hline Model M4i & & & & 0.846 & $24.340^{\star * * *}$ \\
\hline $\mathrm{CA}$ & 0.146 & 0.016 & $0.922^{\star * * *}$ & & \\
\hline Problem Focused_-E & 3.254 & 0.570 & $0.663^{* * * *}$ & & \\
\hline Minimization_-E & -2.895 & 0.587 & $-0.629^{* * * *}$ & & \\
\hline \multirow[t]{2}{*}{ Distress_-E } & 0.696 & 0.305 & $0.254^{*}$ & & \\
\hline & \multicolumn{5}{|c|}{ Emotion Regulation } \\
\hline Predictors & B & $\mathrm{SE} / \mathrm{B}$ & $B$ & $\mathrm{R}^{2}$ adj & $\mathrm{F}$ \\
\hline Model M1j & & & & 0.228 & $7.191^{\star}$ \\
\hline \multirow[t]{2}{*}{ Reprimand_+E } & 0.107 & 0.040 & $0.514^{\star}$ & & \\
\hline & \multicolumn{5}{|c|}{ Emotion Dysregulation } \\
\hline Predictors & B & $\mathrm{SE} / \mathrm{B}$ & $B$ & $\mathrm{R}^{2}$ adj & $\mathrm{F}$ \\
\hline Model M1k & & & & 0.298 & $9.930^{* *}$ \\
\hline $\mathrm{CA}$ & -0.010 & 0.003 & $-0.576^{\star *}$ & & \\
\hline
\end{tabular}

a. Notes. $-\mathrm{E}=$ negative emotion, $+\mathrm{E}=$ positive emotion, $\mathrm{CA}=$ chronological age; $\mathrm{GDA}=$ global developmental age, ${ }^{*} p<0.05,{ }^{* *} p<0.01,{ }^{* * *} p<0.001$. 
Table 7. Predictors of socio-emotional skills of children with intellectual disabilities, including mothers' conversations.

\begin{tabular}{|c|c|c|c|c|c|}
\hline \multirow[b]{3}{*}{ Predictors } & \multicolumn{5}{|c|}{ Mothers' Model } \\
\hline & \multicolumn{5}{|c|}{ ToM-Emotions } \\
\hline & B & $\mathrm{SE} / \mathrm{B}$ & $\beta$ & $\mathrm{R}^{2}$ adj & $\mathrm{F}$ \\
\hline Model M1a & & & & 0.404 & $13.177^{\star *}$ \\
\hline \multirow[t]{2}{*}{ GDA } & 0.122 & 0.034 & $0.661^{* \star}$ & & \\
\hline & \multicolumn{5}{|c|}{ ToM-Beliefs } \\
\hline Predictors & B & $\mathrm{SE} / \mathrm{B}$ & $\beta$ & $\mathrm{R}^{2}$ adj & $\mathrm{F}$ \\
\hline Model M1b & & & & 0.576 & $25.425^{\star * *}$ \\
\hline \multirow[t]{2}{*}{ GDA } & 0.066 & 0.013 & $0.744^{* * *}$ & & \\
\hline & \multicolumn{5}{|c|}{ ToM Task Battery-Total } \\
\hline Predictors & B & $\mathrm{SE} / \mathrm{B}$ & $\beta$ & $\mathrm{R}^{2}$ adj & $\mathrm{F}$ \\
\hline Model M1c & & & & 0.519 & $20.409^{* * *}$ \\
\hline \multirow[t]{2}{*}{ GDA } & 0.132 & 0.029 & $0.739^{* * *}$ & & \\
\hline & \multicolumn{5}{|c|}{ ToM Task Battery-Affective } \\
\hline Predictors & B & $\mathrm{SE} / \mathrm{B}$ & $B$ & $\mathrm{R}^{2}$ adj & $\mathrm{F}$ \\
\hline Model M1d & & & & 0.617 & $28.393^{* * *}$ \\
\hline GDA & 0.075 & 0.014 & $0.800^{* * *}$ & & \\
\hline Model M2d & & & & 0.749 & $26.313^{* * *}$ \\
\hline GDA & 0.080 & 0.011 & $0.855^{* * *}$ & & \\
\hline \multirow[t]{2}{*}{ SES } & 0.195 & 0.064 & $0.376^{* *}$ & & \\
\hline & \multicolumn{5}{|c|}{ ToM Task Battery-Cognitive } \\
\hline Predictors & B & $\mathrm{SE} / \mathrm{B}$ & $\beta$ & $\mathrm{R}^{2}$ adj & $\mathrm{F}$ \\
\hline Model M1e & & & & 0.194 & $5.082^{\star}$ \\
\hline \multirow[t]{2}{*}{ CA } & 0.029 & 0.013 & $0.491^{*}$ & & \\
\hline & \multicolumn{5}{|c|}{ ToM Task Battery-Mixed } \\
\hline Predictors & B & $\mathrm{SE} / \mathrm{B}$ & $\beta$ & $\mathrm{R}^{2}$ adj & $\mathrm{F}$ \\
\hline Model M1f & & & & 0.198 & $4.947^{\star}$ \\
\hline \multirow[t]{2}{*}{ GDA } & 0.025 & 0.011 & $0.498^{*}$ & & \\
\hline & \multicolumn{5}{|c|}{ ToMi-Total } \\
\hline Predictors & B & $\mathrm{SE} / \mathrm{B}$ & $\beta$ & $\mathrm{R}^{2}$ adj & $\mathrm{F}$ \\
\hline Model M1g & & & & 0.473 & $12.661^{* *}$ \\
\hline \multirow[t]{2}{*}{ CA } & 0.086 & 0.024 & $0.717^{* *}$ & & \\
\hline & \multicolumn{5}{|c|}{ ToMi-Thoughts } \\
\hline Predictors & B & $\mathrm{SE} / \mathrm{B}$ & $\beta$ & $\mathrm{R}^{2}$ adj & $\mathrm{F}$ \\
\hline Model M1h & & & & 0.501 & $16.031^{* * *}$ \\
\hline $\mathrm{CA}$ & 0.105 & 0.026 & $0.731^{* * *}$ & & \\
\hline
\end{tabular}




\section{Continued}

\begin{tabular}{|c|c|c|c|c|c|}
\hline \multirow[b]{2}{*}{ Predictors } & \multicolumn{5}{|c|}{ ToMi-Beliefs } \\
\hline & B & $\mathrm{SE} / \mathrm{B}$ & $\beta$ & $\mathrm{R}^{2}$ adj & $\mathrm{F}$ \\
\hline Model M1i & & & & 0.495 & $15.705^{\star * *}$ \\
\hline CA & 0.110 & 0.028 & $0.727^{\star * *}$ & & \\
\hline Model M2i & & & & 0.628 & $13.685^{\star * * *}$ \\
\hline $\mathrm{CA}$ & 0.142 & 0.027 & $0.938^{\star * *}$ & & \\
\hline QCPEE-Emotion-related verbs & 0.951 & 0.388 & $0.440^{\star}$ & & \\
\hline Model M3i & & & & 0.754 & $16.294^{\star * * *}$ \\
\hline $\mathrm{CA}$ & 0.171 & 0.025 & $1.129^{\star * *}$ & & \\
\hline QCPEE-Emotion-related verbs & 1.962 & 0.484 & $0.908^{* *}$ & & \\
\hline QCPEE-Sadness-related terms & -1.295 & 0.469 & $-0.543^{*}$ & & \\
\hline Model M4i & & & & 0.829 & $19.236^{* * * *}$ \\
\hline $\mathrm{CA}$ & 0.206 & 0.025 & $1.358^{\star * *}$ & & \\
\hline QCPEE-Emotion-related verbs & 2.230 & 0.416 & $1.032^{\star * *}$ & & \\
\hline QCPEE-Sadness-related terms & -1.712 & 0.424 & $-0.718^{\star *}$ & & \\
\hline \multirow[t]{2}{*}{ QCPEE-Joy-related terms } & 0.390 & 0.155 & $0.344^{*}$ & & \\
\hline & \multicolumn{5}{|c|}{ Emotion Regulation } \\
\hline Predictors & B & $\mathrm{SE} / \mathrm{B}$ & $\beta$ & $\mathrm{R}^{2}$ adj & $\mathrm{F}$ \\
\hline Model M1j & & & & 0.274 & $7.797^{\star}$ \\
\hline \multirow[t]{2}{*}{ SES } & 0.060 & 0.022 & $0.561^{\star}$ & & \\
\hline & \multicolumn{5}{|c|}{ Emotion Dysregulation } \\
\hline Predictors & B & $\mathrm{SE} / \mathrm{B}$ & $\beta$ & $\mathrm{R}^{2}$ adj & $\mathrm{F}$ \\
\hline Model M1k & & & & 0.314 & $9.244^{* *}$ \\
\hline $\mathrm{CA}$ & -0.008 & 0.003 & $-0.593^{\star *}$ & & \\
\hline
\end{tabular}

a. Notes. $-\mathrm{E}=$ negative emotion, $+\mathrm{E}=$ positive emotion, $\mathrm{CA}=$ chronological age; $\mathrm{GDA}=$ global developmental age, ${ }^{*} p<0.05,{ }^{* *} p<0.01,{ }^{* *} p<0.001$.

As in Table 6, we observed that the same predictors, namely GDA, chronological age and mothers' educational level, explained a certain percentage of the variance in the scores in ToM-Emotions, ToM-Beliefs, the ToM Task Battery and their sub-scores. Chronological age explained 47\%, 50\% and $49 \%$ respectively of the variance in the ToMi and its sub-scores related to thoughts and beliefs. Beyond chronological age, three other predictors linked to emotion-related conversations also explained $83 \%$ of the variance in ToMi-Beliefs scores. The model M4i includes therefore the following predictors chronological age $(\beta=$ $1.358 ; p \leq 0.001)$, the number of verbs related to emotions $(\beta=1.032 ; p \leq 0.001)$, and the number of terms related to sadness $(\beta=-0.718 ; p<0.01)$ and joy $(\beta=$ $0.344 ; p<0.05)$. Finally, $27 \%$ of the variance in emotion regulation and dysregulation was explained respectively by mothers' educational level $(\beta=0.561 ; p<$ $0.05)$, and $31 \%$ by children's chronological age $(\beta=-0.593 ; p<0.01)$. 
Links between father' ERSBs, individual father' and children's characteristics and ToM and ER profiles in children with IDs.

Table 8 presents the results concerning significant predictors, including fathers' emotion-related reactions, of competences in ToM or ER of children with IDs.

For ToM, children's chronological age explained 36\% and 63\% respectively of the variance in the scores in ToM-Emotions and the ToM Task Battery, while GDA explained $38 \%$ of the variance in scores in ToM-Beliefs. The affective and mixed sub-scores of the ToM Task Battery were explained by various specific reactions. A Model P3d including chronological age $(\beta=1.013 ; p<0.001)$, encouragement to positive emotions $(\beta=-0.574 ; p<0.01)$, and socialization in reaction to positive emotions $(\beta=0.322 ; p<0.05)$ explained $89 \%$ of the variance in the affective score, while $79 \%$ of the variance in the mixed score was explained by punitive reactions to negative emotions $(\beta=0.907 ; p<0.01)$. Concerning fathers' perceptions of their children's ToM skills (measured by ToMi), chronological age explained $92 \%$ and $51 \%$ of the variance in the total score and the score for socio-emotional abilities. GDA explained $42 \%$ of the variance in the ToMi-Beliefs sub-score, whereas, a Model P3h including GDA $(\beta=0.666 ; p=$ $0.000)$, punitive $(\beta=0.262 ; p<0.01)$ and comforting reactions $(\beta=0.239 ; p<$ 0.05 ) explained $96 \%$ of the variance in the subscore of the ToMi related to thoughts. GDA alone explained $52 \%$ of the variance in emotion dysregulation ( $\beta$ $=-0.756 ; p<0.05)$.

Table 9 presents the results concerning significant predictors, including fathers' emotion-related conversations, of competences in ToM or ER of children with IDs.

The results revealed that children's chronological age explained $43 \%, 63 \%$, $55 \%, 92 \%$, and $48 \%$ respectively of the variance in ToM-Emotions $(\beta=0.713 ; p$ $<0.05)$, the total $(\beta=0.829 ; p<0.05)$ and the affective subscore $(\beta=0.788 ; p<$ $0.05)$ of the ToM Task Battery, and the total $(\beta=0.966 ; p \leq 0.001)$ and the socio-emotional subscore $(\beta=0.746 ; p<0.05)$ of the ToMi. The children's GDA explained $91 \%$ of the variance in the ToMi sub-score related to thoughts $(\beta=$ $0.960 ; p \leq 0.001)$. Regarding ER, the fathers' educational level $(\beta=1.150 ; p \leq$ 0.001 ) and their emotion-related conversations with their children (QCPEE score; $\beta=0.525 ; p<0.05)$ explained $92 \%$ of the variance. The children's chronological age $(\beta=-0.952 ; p \leq 0.001)$ explained $89 \%$ of the variance in their emotion dysregulation.

\section{Discussion}

The present study investigated how parents support the social and emotional competences of their children with IDs. Specifically, we explored the link between parents' ERSBs, notably reactions and conversations, and their children's ToM and ER competences. Regression analysis revealed that certain individual characteristics and reactions or conversations account for some of the variance 
E. Jacobs et al.

Table 8. Predictors of socio-emotional skills of children with intellectual disabilities, including fathers' reactions

\begin{tabular}{|c|c|c|c|c|c|}
\hline \multicolumn{6}{|c|}{ Fathers' Model } \\
\hline \multirow[b]{2}{*}{ Predictors } & \multicolumn{5}{|c|}{ ToM-Emotions } \\
\hline & B & $\mathrm{SE} / \mathrm{B}$ & $\beta$ & $\mathrm{R}^{2}$ adj & $\mathrm{F}$ \\
\hline Model P1a & & & & 0.362 & $6.098^{*}$ \\
\hline \multirow[t]{2}{*}{$\mathrm{CA}$} & 0.086 & 0.035 & $0.658^{*}$ & & \\
\hline & \multicolumn{5}{|c|}{ ToM-Beliefs } \\
\hline Predictors & B & $\mathrm{SE} / \mathrm{B}$ & $\beta$ & $\mathrm{R}^{2}$ adj & $\mathrm{F}$ \\
\hline Model P1b & & & & 0.383 & $6.587^{*}$ \\
\hline \multirow[t]{2}{*}{ GDA } & 0.074 & 0.029 & $0.672^{*}$ & & \\
\hline & \multicolumn{5}{|c|}{ ToM Task Battery-Total } \\
\hline Predictors & B & $\mathrm{SE} / \mathrm{B}$ & $\beta$ & $\mathrm{R}^{2}$ adj & $\mathrm{F}$ \\
\hline Model P1c & & & & 0.634 & $16.590^{* *}$ \\
\hline \multirow[t]{2}{*}{ CA } & 0.069 & 0.017 & $0.821^{* *}$ & & \\
\hline & \multicolumn{5}{|c|}{ ToM Task Battery-Affective } \\
\hline Predictors & B & $\mathrm{SE} / \mathrm{B}$ & $\beta$ & $\mathrm{R}^{2}$ adj & $\mathrm{F}$ \\
\hline Model P1d & & & & 0.449 & $7.517^{*}$ \\
\hline $\mathrm{CA}$ & 0.021 & 0.008 & $0.720^{*}$ & & \\
\hline Model P2d & & & & 0.793 & $16.296^{* *}$ \\
\hline $\mathrm{CA}$ & 0.026 & 0.005 & $0.903^{\star *}$ & & \\
\hline Encouragement_+E & -0.190 & 0.053 & $-0.600^{*}$ & & \\
\hline Model P3d & & & & 0.894 & $23.589^{\star *}$ \\
\hline $\mathrm{CA}$ & 0.029 & 0.004 & $1.013^{\star * *}$ & & \\
\hline Encouragement_+E & -0.182 & 0.038 & $-0.574^{\star *}$ & & \\
\hline \multirow[t]{2}{*}{ Socialization_+E } & 0.109 & 0.042 & $0.322^{\star}$ & & \\
\hline & \multicolumn{5}{|c|}{ ToM Task Battery-Mixed } \\
\hline Predictors & B & $\mathrm{SE} / \mathrm{B}$ & $\beta$ & $\mathrm{R}^{2}$ adj & $\mathrm{F}$ \\
\hline Model P1e & & & & 0.793 & $27.835^{\star \star}$ \\
\hline \multirow[t]{2}{*}{ Punishment_-E } & 0.229 & 0.043 & $0.907^{\star *}$ & & \\
\hline & \multicolumn{5}{|c|}{ ToMi-Total } \\
\hline Predictors & B & $\mathrm{SE} / \mathrm{B}$ & $\beta$ & $\mathrm{R}^{2}$ adj & $\mathrm{F}$ \\
\hline Model P1f & & & & 0.919 & $69.426^{* * *}$ \\
\hline \multirow[t]{2}{*}{$\mathrm{CA}$} & 0.115 & 0.014 & $0.966^{* * * *}$ & & \\
\hline & \multicolumn{5}{|c|}{ ToMi-Socioemotional } \\
\hline Predictors & B & $\mathrm{SE} / \mathrm{B}$ & $\beta$ & $\mathrm{R}^{2}$ adj & $\mathrm{F}$ \\
\hline Model P1g & & & & 0.512 & $10.460^{*}$ \\
\hline $\mathrm{CA}$ & 0.069 & 0.021 & $0.753^{*}$ & & \\
\hline
\end{tabular}




\section{Continued}

\begin{tabular}{|c|c|c|c|c|c|}
\hline \multirow[b]{2}{*}{ Predictors } & \multicolumn{5}{|c|}{ ToMi-Thoughts } \\
\hline & B & $\mathrm{SE} / \mathrm{B}$ & $\beta$ & $\mathrm{R}^{2}$ adj & $\mathrm{F}$ \\
\hline Model P1h & & & & 0.871 & $61.880^{* * *}$ \\
\hline GDA & 0.306 & 0.039 & $0.941^{\star * *}$ & & \\
\hline Model P2h & & & & 0.932 & $62.230^{* * *}$ \\
\hline GDA & 0.268 & 0.031 & $0.823^{* * *}$ & & \\
\hline Punishment_-E & 0.746 & 0.263 & $0.274^{\star}$ & & \\
\hline Model P3h & & & & 0.966 & $85.777^{\star * *}$ \\
\hline GDA & 0.217 & 0.029 & $0.666^{* * *}$ & & \\
\hline Punishment_-E & 0.713 & 0.186 & $0.262^{\star *}$ & & \\
\hline \multirow[t]{2}{*}{ Comforting_-E } & 1.054 & 0.372 & $0.239^{*}$ & & \\
\hline & \multicolumn{5}{|c|}{ ToMi-Beliefs } \\
\hline Predictors & B & $\mathrm{SE} / \mathrm{B}$ & $\beta$ & $\mathrm{R}^{2}$ adj & $\mathrm{F}$ \\
\hline Model P1i & & & & 0.416 & $7.421^{*}$ \\
\hline \multirow[t]{2}{*}{ GDA } & 0.217 & 0.080 & $0.694^{*}$ & & \\
\hline & \multicolumn{5}{|c|}{ Emotion Dysregulation } \\
\hline Predictors & B & $\mathrm{SE} / \mathrm{B}$ & $\beta$ & $\mathrm{R}^{2}$ adj & $\mathrm{F}$ \\
\hline Model P1j & & & & 0.518 & $10.685^{\star}$ \\
\hline GDA & -0.034 & 0.010 & $-0.756^{*}$ & & \\
\hline
\end{tabular}

a. Notes. $-\mathrm{E}=$ negative emotion, $+\mathrm{E}=$ positive emotion, $\mathrm{CA}=$ chronological age; $\mathrm{GDA}=$ global developmental age, ${ }^{*} p<0.05,{ }^{* *} p<0.01,{ }^{* * *} p<0.001$.

Table 9. Predictors of socio-emotional skills of children with intellectual disabilities, including fathers' conversations.

\begin{tabular}{|c|c|c|c|c|c|}
\hline \multicolumn{6}{|c|}{ Fathers' Model } \\
\hline \multirow[b]{2}{*}{ Predictors } & \multicolumn{5}{|c|}{ ToM-Emotions } \\
\hline & $\mathrm{B}$ & $\mathrm{SE} / \mathrm{B}$ & $\beta$ & $\mathrm{R}^{2}$ adj & $\mathrm{F}$ \\
\hline Model P1a & & & & 0.426 & $6.197^{\star}$ \\
\hline \multirow[t]{2}{*}{$\mathrm{CA}$} & 0.075 & 0.030 & $0.713^{*}$ & & \\
\hline & \multicolumn{5}{|c|}{ ToM Task Battery-Total } \\
\hline Predictors & B & $\mathrm{SE} / \mathrm{B}$ & $\beta$ & $\mathrm{R}^{2}$ adj & $\mathrm{F}$ \\
\hline Model P1b & & & & 0.635 & $13.185^{*}$ \\
\hline \multirow[t]{2}{*}{ CA } & 0.066 & 0.018 & $0.829^{*}$ & & \\
\hline & \multicolumn{5}{|c|}{ ToM Task Battery-Affective } \\
\hline Predictors & B & $\mathrm{SE} / \mathrm{B}$ & $\beta$ & $\mathrm{R}^{2}$ adj & $\mathrm{F}$ \\
\hline Model P1c & & & & 0.546 & $8.214^{\star}$ \\
\hline CA & 0.020 & 0.007 & $0.788^{*}$ & & \\
\hline
\end{tabular}




\section{Continued}

\begin{tabular}{|c|c|c|c|c|c|}
\hline \multirow[b]{2}{*}{ Predictors } & \multicolumn{5}{|c|}{ ToMi-Total } \\
\hline & B & $\mathrm{SE} / \mathrm{B}$ & $\beta$ & $\mathrm{R}^{2}$ adj & $\mathrm{F}$ \\
\hline Model P1d & & & & 0.919 & $69.426^{* * *}$ \\
\hline \multirow[t]{2}{*}{$\mathrm{CA}$} & 0.115 & 0.014 & $0.966^{\star * *}$ & & \\
\hline & \multicolumn{5}{|c|}{ ToMi-Socioemotional } \\
\hline Predictors & B & $\mathrm{SE} / \mathrm{B}$ & $\beta$ & $\mathrm{R}^{2}$ adj & $\mathrm{F}$ \\
\hline Model P1e & & & & 0.483 & $7.547^{*}$ \\
\hline \multirow[t]{2}{*}{$\mathrm{CA}$} & 0.069 & 0.025 & $0.746^{*}$ & & \\
\hline & \multicolumn{5}{|c|}{ ToMi-Thoughts } \\
\hline Predictors & B & $\mathrm{SE} / \mathrm{B}$ & $\beta$ & $\mathrm{R}^{2}$ adj & $\mathrm{F}$ \\
\hline Model P1f & & & & 0.909 & $70.736^{\star * *}$ \\
\hline \multirow[t]{2}{*}{ GDA } & 0.285 & 0.034 & $0.960^{\star * *}$ & & \\
\hline & \multicolumn{5}{|c|}{ Emotion Regulation } \\
\hline Predictors & B & $\mathrm{SE} / \mathrm{B}$ & $\beta$ & $\mathrm{R}^{2} \mathrm{adj}$ & $\mathrm{F}$ \\
\hline Model P1g & & & & 0.704 & $17.685^{\star *}$ \\
\hline SES & 0.144 & 0.034 & $0.864^{\star \star}$ & & \\
\hline Model P2g & & & & 0.916 & $39.279^{\star * *}$ \\
\hline SES & 0.192 & 0.022 & $1.150^{* * *}$ & & \\
\hline \multirow[t]{2}{*}{ QCPEE } & 0.241 & 0.060 & $0.525^{*}$ & & \\
\hline & \multicolumn{5}{|c|}{ Emotion Dysregulation } \\
\hline Predictors & B & $\mathrm{SE} / \mathrm{B}$ & $\beta$ & $\mathrm{R}^{2} \mathrm{adj}$ & $\mathrm{F}$ \\
\hline Model P1h & & & & 0.890 & $57.573^{\star * *}$ \\
\hline $\mathrm{CA}$ & -0.014 & 0.002 & $-0.952^{* * *}$ & & \\
\hline
\end{tabular}

a. Notes. $-\mathrm{E}=$ negative emotion, $+\mathrm{E}=$ positive emotion, $\mathrm{CA}=$ chronological age; $\mathrm{GDA}=$ global developmental age, ${ }^{\star} p<0.05,{ }^{* *} p<0.01,{ }^{* *} p<0.001$.

in ToM and ER profiles in children with IDs. This variability was observed according to parents' gender, educational level, ERSBs as reactions and conversations, including the emotional lexicon used.

Regarding children's ToM, certain ERSBs of parents appeared to explain some part of the variance of these competences.

The understanding of affective mental states (ToM Task Battery-Affective) was explained by children's chronological age and by reactions of encouragement and socialization displayed by fathers. A positive beta indicates that fathers' socialization supported affective ToM. When fathers explain to their children why an emotional behavior could be socially appropriate (Ladouceur, Reid, \& Jacques, 2002), it may help children gain a better understanding of the consequences of emotions. With a negative beta, encouragement appeared to be unsupportive for the understanding of affective mental states in children with IDs. Encouragement refers to an acceptance by fathers of their children's emo- 
tions and encouragement to express them (Coutu, Dubeau, Provost, Royer, \& Lavigueur, 2002; Fabes et al., 2002; Ladouceur et al., 2002). For children with IDs, the older they were, the more fathers' encouragement of positive emotions appeared to harm their affective ToM. As Mazzone and Nader-Grosbois (2017b) observed in children with autistic spectrum disorder, encouragement could be inappropriate and counterproductive, notably for children with a certain life experience.

Some variance in the comprehension of mixed mental states (the mixed score in the ToM Task Battery) was explained by punitive reactions to children's negative emotions. In the mothers' model, punitive reactions were combined with GDA, whereas in the fathers' model, it was purely the punitive reactions that explained the variance. This result is surprising, but it could perhaps be explained by the content of the items that measured punitive reactions. Four of the six items consisted of possible parental responses based on potential consequences (such as a ban on watching TV or playing in the playground). This strategy could in fact help children to understand a conditional link between, for example, beliefs or thoughts and certain types of knowledge or action. Conversely, Denham (2007) concluded that punitive responses could be beneficial for TD children, but for their ER.

Concerning parents' perception of their children's comprehension of mental states, a difference was observed between mothers and fathers. Firstly, in the mothers' models, problem-focused reactions, minimization and distress in response to children's negative emotions explained, in combination with children chronological age, $85 \%$ of the variance in the ToMi-Beliefs subscore. Concretely, it appeared that the more mothers helped their children to find a solution and displayed distress, the more they perceived their children as able to understand beliefs. Problem-focused reactions as a supportive strategy has already been associated with better emotional competences in typically developing children (Fabes et al., 2002). Such reactions involved mothers helping their children to think about solutions or to work out a socially appropriate response (Coutu et al., 2002; Fabes et al., 2002), and could therefore be related to cognitive aspects. Distress explained part of the variance with a positive beta. This may seem surprising, but because distress was related to mothers' irritation in social situations, it may give children an insight into their mothers' thinking, and hence into the cognition of others. Moreover, distress is a reaction which is particularly observed in parents of children with IDs (Jacobs et al., 2019). Minimization negatively explained the part of the variance, implying that the more mothers react in this way, the less children understand beliefs. As an unsupportive strategy, minimization reduces opportunities for mothers to explain cognitive mental states. Variance in the ToMi-Beliefs subscore was also explained by children's chronological age and by mothers' use of emotion-related verbs or terms linked to sadness and joy. The more mothers employed emotion-related verbs or terms linked to joy, the more they perceived their children as competent to understand beliefs. Conversely, the more they used terms linked to sadness, the more they 
saw their children as weak in these ToM components. The link between the use of emotion-related terms and comprehension of belief has been reported in particular in a study of preschoolers (Adrian, Clemente, Villanueva, \& Rieffe, 2005). Secondly, in the fathers' model related to reactions, the perception of children's understanding of thoughts was explained by children's GDA and fathers' employment of punishment and comforting in response to children's negative emotions. As it was the case for the ToM Task Battery-mixed score, an explanation may be that by expressing potential consequences, fathers help their children to appreciate mental states linked to "thinking", "intentions related to moral responsibility" and "knowledge", which were assessed by the 19 items of the ToMi-Thoughts subscore. Likewise, by comforting, namely by trying to redirect children's cognition in uncomfortable situations (Coutu et al., 2002; Fabes et al., 2002), fathers may help them to understand the same kind of cognitive mental state.

These results underline the specific contribution of mothers and fathers' ERSBs to the ToM profiles of children with IDs: mothers reactions and conversations may contribute specifically to cognitive ToM, whereas fathers' reactions may promote affective and cognitive ToM.

Concerning ER, in the maternal models, reprimands explained 23\% of the variance in children's ER, whereas emotion dysregulation was explained by children's chronological age. Emotion-related conversations did not explain these emotion regulation scores. This result indicates that mothers' use of reprimands could explain ER abilities. This outcome is not as surprising as it may seem. Reprimanding was defined as avoiding positive emotions (Ladouceur et al., 2002). By doing this, as Denham (2007) suggested, mothers may signal to their children that better ER is expected. Children have to regulate their positive emotions in order to gain their mothers' attention. Similarly, Eisenberg et al. (1999) observed that parents' emotional control could be concomitant with children's ER. Conversely, in the fathers' model, no reaction explained part of the variance in ER scores. However, emotion-related conversations, combined with the fathers' educational level, explained $92 \%$ of the variance in ER. Likewise, parents' detailed discussion of emotions has been related to better ER in preschoolers (Morelen \& Suveg, 2012).

When considering these results, certain limitations have to be taken into account. In the regressions analyses, we entered individual characteristics in Step 1. Yet Spearman correlations as well as the literature (Mazzone \& Nader-Grosbois, 2017c) have shown that the chronological age and developmental age of children have an important effect on ToM and ER. In the regression process, these age-related variables may therefore have explained most of the variance, leaving nothing for the ERSBs to explain. However, deleting Step 1 seemed inconceivable, because parents adapt their behavior according to their children's age. It would be interesting to continue exploring bidirectional links between ERSBs and the emotional and social competences of children with IDs. At a methodological level, adding a measure of parental emotional expression, such as the 
measure of Dimensions of Openness to Emotion developed by Reicherts (2007), would be interesting, in order to appreciate whether these dimensions affect ERSBs and ToM and ER profiles of children with IDs. Fabes, Leonard, Kupanoff and Martin (2001) as well as Mirabile (2014) have observed that parents who report a high level of unsupportive reactions also express more negative emotions, and that these parents have children with poorer ER competences. It could also be interesting to include another measure of ERSBs, for example an observational measure, as Rodas et al. (2016) did. Regarding conversations, new analyses could be applied by integrating data obtained using a new observational design and coding measure (currently undergoing valuation) for conversations about mental states between parents and children (Jacobs \& Nader-Grosbois, 2017).

The present outcomes highlight the importance of investigating mothers' and fathers' ERSBs separately, as it has previously been shown for parents of typically developing children (e.g. Baker, Fenning, \& Crnic, 2011; Eisenberg et al., 1996; Hughes \& Gullone, 2010; McElwain, Halberstadt, \& Volling, 2007) or children with Autistic Spectrum Disorder (Mazzone \& Nader-Grosbois, 2017a, 2017b). Likewise, the results suggest that parents socialize affective and cognitive ToM differently, as suggested by McElwain et al. (2007). While working with parents, to foster cognitive ToM in children with IDs, professionals could encourage fathers to use comforting responses and mothers to discuss solutions and feelings of joy or sadness during their conversations with their children. Mothers and fathers also seem to support ER differently. Mothers appear to promote ER competences by reprimanding positive emotions while fathers stimulate them during emotional discourse. This research highlights the importance of paying attention to parents' individual profiles in terms of reactions and conversations. During parental guidance, professionals should emphasize the particular role played by each parent in the emotion socialization of their child with IDs.

However, the present results do not give fixed guidelines about what parents should do. We cannot draw any premature conclusions, in terms of supportive vs. unsupportive strategy. For example, fathers' encouragement cannot be considered as negative for children's ToM skills, but rather as a strategy which has no leverage effect. ERSBs are particularly complex because they are dynamic (Rogers et al., 2016). Parents constantly have to adapt, in a contingent way and in different contexts, to their children's characteristics and competences. The regression analyses demonstrate the important role of children's individual characteristics. Therefore, the first step in a clinical context is to make parents aware of their children' competences and life experience, so that they adjust their ERSBs.

\section{Acknowledgements}

We wish to thank the Marguerite-Marie Delacroix Foundation for its financial support for this research. We are also grateful to the Chair Baron Frère and to all the parents and children who took part in this research. 


\section{Conflicts of Interest}

The authors declare no conflicts of interest regarding the publication of this paper.

\section{References}

Adrian, J. E., Clemente, R. A., Villanueva, L., \& Rieffe, C. (2005). Parent-Child Picture-Book Reading, Mothers' Mental State Language and Children's Theory of Mind. Journal of Child Language, 32, 673-686. https://doi.org/10.1017/S0305000905006963

Baglio, G., Blasi, V., Sangiuliano Intra, F., Castelli, I., Massaro, D., Baglio, F., \& Marchetti, A. (2016). Social Competence in Children with Borderline Intellectual Functioning: Delayed Development of Theory of Mind across All Complexity Levels. Frontiers in Psychology, 7, 1604. https://doi.org/10.3389/fpsyg.2016.01604

Baker, J. K., Fenning, R. M., \& Crnic, K. A. (2011). Emotion Socialization by Mothers and Fathers: Coherence among Behaviors and Associations with Parent Attitudes and Children's Social Competence. Social Development, 20, 412-430.

https://doi.org/10.1111/j.1467-9507.2010.00585.x

Baker, J. K., Fenning, R. M., Crnic, K. A., Baker, B. L., \& Blacher, J. (2007). Prediction of Social Skills in 6-Year-Old Children with and without Developmental Delays: Contributions of Early Regulation and Maternal Scaffolding. Journal Information, 112, 375-391. https://doi.org/10.1352/0895-8017(2007)112[0375:POSSIY]2.0.CO;2

Baurain, C., \& Nader-Grosbois, N. (2012). Socio-Emotional Regulation in Children with Intellectual Disability and Typically Developing Children in Interactive Contexts. ALTER-European Journal of Disability Research/Revue Européenne de Recherche sur le Handicap, 6, 75-93. https://doi.org/10.1016/j.alter.2012.02.001

Baurain, C., \& Nader-Grosbois, N. (2013a). Compétences sociales et émotionnelles: Enfant typique et déficient intellectuel. Saarbücken: Presses Académiques Francophones.

Baurain, C., \& Nader-Grosbois, N. (2013b). Theory of Mind, Socio-Emotional Problem-Solving, Socio-Emotional Regulation in Children with Intellectual Disability and in Typically Developing Children. Journal of Autism and Developmental Disorder, 43, 1080-1097. https://doi.org/10.1007/s10803-012-1651-4

Berkovits, L., \& Baker, B. L. (2014). Emotion Dysregulation and Social Competence: Stability, Change and Predictive Power. Journal of Intellectual Disability Research, 58, 765-776. https://doi.org/10.1111/jir.12088

Charman, T., \& Campbell, A. (2002). Theory of Mind and Social Competence in Individuals with a Mental Handicap. Journal of Developmental and Physical Disabilities, 14, 263-276. https://doi.org/10.1023/A:1016076405731

Cicchetti, D., Ackerman, B. P., \& Izard, C. E. (1995). Emotions and Emotion Regulation in Developmental Psychopathology. Development and Psychopathology, 7, 1-10. https://doi.org/10.1017/S0954579400006301

Coutu, S., Dubeau, D., Provost, M., Royer, N., \& Lavigueur, S. (2002). Validation de la version française du questionnaire: Coping with Children's Negative Emotions Scale-CCNES. Canadian Journal of Behavioural Science/Revue canadienne des sciences du comportement, 34, 230-234. https://doi.org/10.1037/h0087175

Daffe, V., \& Nader-Grosbois, N. (2009). Parental Reactions toward Their Children's Emotions: Combined Version of Two Questionnaires. In N. Nader-Grosbois (Ed.), Resilience, Regulation and Quality of Life (pp. 143-159). Louvain-la-Neuve: Presses Universitaires de Louvain.

Danielsson, H., Henry, L., Messer, D., \& Rönnberg, J. (2012). Strengths and Weaknesses 
in Executive Functioning in Children with Intellectual Disability. Research in Developmental Disabilities, 33, 600-607. https://doi.org/10.1016/j.ridd.2011.11.004

Denham, S. A. (2007). Dealing with Feelings: How Children Negotiate the Worlds of Emotions and Social Relationships. Cognition, Brain, Behavior, 11, 1.

Eisenberg, N., \& Spinrad, T. L. (2004). Emotion-Related Regulation: Sharpening the Definition. Child Development, 75, 334-339. https://doi.org/10.1111/j.1467-8624.2004.00674.x

Eisenberg, N., Cumberland, A., \& Spinrad, T. L. (1998). Parental Socialization of Emotion. Psychological Inquiry, 9, 241-273. https://doi.org/10.1207/s15327965pli0904_1

Eisenberg, N., Fabes, R. A., \& Murphy, B. C. (1996). Parents' Reactions to Children's Negative Emotions: Relations to Children's Social Competence and Comforting Behavior. Child Development, 67, 2227-2247. https://doi.org/10.2307/1131620

Eisenberg, N., Fabes, R. A., Shepard, S. A., Guthrie, I. K., Murphy, B. C., \& Reiser, M. (1999). Parental Reactions to Children's Negative Emotions: Longitudinal Relations to Quality of Children's Social Functioning. Child Development, 70, 513-534.

https://doi.org/10.1111/1467-8624.00037

Fabes, R. A., Leonard, S. A., Kupanoff, K., \& Martin, C. L. (2001). Parental Coping with Children's Negative Emotions: Relations with Children's Emotional and Social Responding. Child Development, 72, 907-920. https://doi.org/10.1111/1467-8624.00323

Fabes, R. A., Poulin, R. E., Eisenberg, N., \& Madden-Derdich, D. A. (2002). The Coping with Children's Negative Emotions Scale (CCNES): Psychometric Properties and Relations with Children's Emotional Competence. Marriage \& Family Review, 34, 285-310. https://doi.org/10.1300/J002v34n03_05

Fiasse, C., \& Nader-Grosbois, N. (2012). Perceived Social Acceptance, Theory of Mind and Social Adjustment in Children with Intellectual Disabilities. Research in Developmental Disabilities, 33, 1871-1880. https://doi.org/10.1016/j.ridd.2012.05.017

Flavell, J. H. (1986). The Development of Children's Knowledge about the Appearance-Reality Distinction. American Psychologist, 41, 418-425. https://doi.org/10.1037/0003-066X.41.4.418

Flavell, J. H. (1999). Cognitive Development: Children's Knowledge about the Mind. Annual Review of Psychology, 50, 21-45. https://doi.org/10.1146/annurev.psych.50.1.21

Flavell, J. H., Everett, B. A., Croft, K., \& Flavell, E. R. (1981). Young Children's Knowledge about Visual Perception: Further Evidence for the Level 1-Level 2 Distinctions. Developmental Psychology, 17, 99-103. https://doi.org/10.1037/0012-1649.17.1.99

Garitte, C. (2003). La reconnaissance des expressions faciales chez des enfants de 8 ans d'âge réel et/ou mental: Processus cognitifs ou sociaux? Les troubles du comportement en milieu scolaire. Approche Neuropsychologique des Apprentissages chez l'enfant, 71, 48-52.

Giaouri, S., Alevriadou, A., \& Tsakiridou, E. (2010). Theory of Mind Abilities in Children with Down Syndrome and Non-Specific Intellectual Disabilities: An Empirical Study with Some Educational Implications. Procedia-Social and Behavioral Sciences, 2, 3883-3887. https://doi.org/10.1016/j.sbspro.2010.03.609

Gottman, J. M., \& DeClaire, J. (1997). Raising an Emotionally Intelligent Child: The Heart of Parenting. New York: Simon \& Schuster.

Gottman, J. M., Katz, L. F., \& Hooven, C. (1996). Parental Meta-Emotion Philosophy and the Emotional Life of Families: Theoretical Models and Preliminary Data. Journal of Family Psychology, 10, 243-268. https://doi.org/10.1037/0893-3200.10.3.243

Green, S., \& Baker, B. L. (2011). Parents' Emotion Expression as a Predictor of Child's 
Social Competence: Children with or without Intellectual Disability. Journal of Intellectual Disability Research, 55, 324-338. https://doi.org/10.1111/j.1365-2788.2010.01363.x

Guralnick, M. J. (1992). A Hierarchical Model for Understanding Children's Peer-Related Social Competence. In S. Odom, S. McConnell, \& M. McEvoy (Eds.), Social Competence of Young Children with Disabilities: Issues and Strategies for Intervention (pp. 37-64). Baltimore, MD: Brookes Publishing.

Guralnick, M. J. (1999). Family and Child Influences on the Peer-Related Social Competence of Young Children with Developmental Delays. Developmental Disabilities Research Reviews, 5, 21-29. https://doi.org/10.1002/(SICI)1098-2779(1999)5:1<21::AID-MRDD3>3.0.CO;2-O

Havighurst, S., \& Harley, A. (2007). Tuning in to Kids: Emotionally Intelligent Parenting: Program Manual. Melbourne: University of Melbourne.

Hippolyte, L., Iglesias, K., Van der Linden, M., \& Barisnikov, K. (2010). Social Reasoning Skills in Adults with Down Syndrome: The Role of Language, Executive Functions and Socio-Emotional Behaviour. Journal of Intellectual Disability Research, 54, 714-726. https://doi.org/10.1111/j.1365-2788.2010.01299.x

Houssa, M., Mazzone, S., \& Nader-Grosbois, N. (2014). Validation d'une version francophone de l'inventaire de la Théorie de l'Esprit (ToMI-vf). Revue Européenne de Psychologie Appliquée/European Review of Applied Psychology, 64, 169-179. https://doi.org/10.1016/j.erap.2014.02.002

Hughes, C. (2011). Social Understanding and Social Lives: From Toddlerhood through to the Transition to School. Hove: Psychology Press. https://doi.org/10.4324/9780203813225

Hughes, E. K., \& Gullone, E. (2010). Parent Emotion Socialisation Practices and Their Associations with Personality and Emotion Regulation. Personality and Individual Differences, 49, 694-699. https://doi.org/10.1016/j.paid.2010.05.042

Hutchins, T. L., Bonazinga, L. A., Prelock, P. A., \& Taylor, R. S. (2008). Beyond False Beliefs: The Development and Psychometric Evaluation of the Perceptions of Children's Theory of Mind Measure-Experimental Version (PCToMM-E). Journal of Autism and Developmental Disorder, 38, 143-155. https://doi.org/10.1007/s10803-007-0377-1

Hutchins, T. L., Prelock, P. A., \& Bonazinga, L. (2012). Psychometric Evaluation of the Theory of Mind Inventory (ToMI): A Study of Typically Developing Children and Children with Autism Spectrum Disorder. Journal of Autism and Developmental Disorder, 42, 327-341. https://doi.org/10.1007/s10803-011-1244-7

Jacobs, E., \& Nader-Grosbois, N. (2017). Grille de Conversations autour des états mentaux Parent-Enfant. Louvain-La-Neuve: UCLOUVAIN.

Jacobs, E., \& Nader-Grosbois, N. (In Preparation). Affective and Cognitive Theory of Mind in Children with Intellectual Disabilities: How to Train Them to Foster Social Adjustment and Emotion Regulation?

Jacobs, E., \& Nader-Grosbois, N. (In Revision). Social Information Processing: A Key to Supporting Emotion Regulation and Social Behaviors in Children with Intellectual Disabilities? Research in Developmental Disabilities.

Jacobs, E., Mazzone, S., Simon, P., \& Nader-Grosbois, N. (2019). Unforeseen Influence of Parents' Socialization Behaviors on Social Adjustment of Children with Intellectual Disabilities Psychology.

Ladouceur, C., Reid, L., \& Jacques, A. (2002). Construction et validation du Questionnaire sur les réactions parentales aux émotions positives exprimées par l'enfant. Canadian 
Journal of Behavioural Science, 34, 8-18.

https://doi.org/10.1037/h0087150

Mazzone, S., \& Nader-Grosbois, N. (2017a). Emotion-Related Socialization Behaviours in Parents of Children with an Autism Spectrum Disorder. Psychology, 8, 1134-1160. https://doi.org/10.4236/psych.2017.88074

Mazzone, S., \& Nader-Grosbois, N. (2017b). How Are Parental Reactions to Children's Emotions Linked with Theory of Mind in Children with Autism Spectrum Disorder? Research in Autism Spectrum Disorders, 40, 41-53. https://doi.org/10.1016/j.rasd.2017.05.003

Mazzone, S., \& Nader-Grosbois, N. (2017c). Variability and Predictors of Mothers and Fathers' Socialization Behaviors and Bidirectional Links with Their Preschoolers Socio-Emotional Competences. Journal of Behavioral and Brain Science, 7, 621-653. https://doi.org/10.4236/jbbs.2017.712043

Mazzone, S., Roskam, I., Mikolajczak, M., \& Nader-Grosbois, N. (2017). Do Parents Talk about Emotions with Their Children? The Questionnaire of Parent-Child Conversations about Emotions (QPCCE). Psychology, 8, 987-1007.

https://doi.org/10.4236/psych.2017.87065

McElwain, N. L., Halberstadt, A. G., \& Volling, B. L. (2007). Mother- and Father-Reported Reactions to Children's Negative Emotions: Relations to Young Children's Emotional Understanding and Friendship Quality. Child Development, 78, 1407-1425. https://doi.org/10.1111/j.1467-8624.2007.01074.x

McIntyre, L. L. (2008). Parent Training for Young Children with Developmental Disabilities: Randomized Controlled Trial. American Journal on Mental Retardation, 113, 356-368. https://doi.org/10.1352/2008.113:356-368

Mirabile, S. P. (2014). Parents' Inconsistent Emotion Socialization and Children's Socioemotional Adjustment. Journal of Applied Developmental Psychology, 35, 392-400. https://doi.org/10.1016/j.appdev.2014.06.003

Morelen, D., \& Suveg, C. (2012). A Real-Time Analysis of Parent-Child Emotion Discussions: The Interaction Is Reciprocal. Journal of Family Psychology, 26, 998. https://doi.org/10.1037/a0030148

Nader-Grosbois, N. (2007). Régulation, autorégulation, dysrégulation: Pistes pour l'intervention et la recherche. Bruxelles: Editions Mardaga.

Nader-Grosbois, N. (2011). La théorie de l'esprit: Entre cognition, émotion et adaptation sociale. Bruxelles: De Boeck. https://doi.org/10.3917/dbu.nader.2011.01

Nader-Grosbois, N., \& Houssa, M. (2016). La Batterie de tâches de Théorie de l'esprit: Validation de la version francophone. Enfance, 2016, 141-166. https://doi.org/10.4074/S0013754516002019

Nader-Grosbois, N., \& Mazzone, S. (2015). Validation de la version francophone de l'Emotion Regulation Checklist (ERC-vf). Revue Européenne de Psychologie Appliquée, 65, 29-41. https://doi.org/10.1016/j.erap.2014.10.002

O’Reilly, J., \& Peterson, C. C. (2014). Theory of Mind at Home: Linking Authoritative and Authoritarian Parenting Styles to Children's Social Understanding. Early Child Development and Care, 184, 1934-1947. https://doi.org/10.1080/03004430.2014.894034

Oswald, D. P., \& Ollendick, T. H. (1989). Role Taking and Social Competence in Autism and Mental Retardation. Journal of Autism and Developmental Disorders, 19, 119-127. https://doi.org/10.1007/BF02212723

Pavarini, G., de Hollanda Souza, D., \& Hawk, C. K. (2013). Parental Practices and Theory of Mind Development. Journal of Child and Family Studies, 22, 844-853. 
https://doi.org/10.1007/s10826-012-9643-8

Perner, J., Leekam, H., \& Wimmer, H. (1987). Three-Year-Olds' Difficulty with False Belief: The Case for a Conceptual Deficit. British Journal of Developmental Psychology, 5, 125-137. https://doi.org/10.1111/j.2044-835X.1987.tb01048.x

Perry, N. B., Calkins, S. D., Nelson, J. A., Leerkes, E. M., \& Marcovitch, S. (2012). Mothers' Responses to Children's Negative Emotions and Child Emotion Regulation: The Moderating Role of Vagal Suppression. Developmental Psychobiology, 54, 503-513. https://doi.org/10.1002/dev.20608

Reicherts, M. (2007). Dimensions of Openness to Emotions (DOE): A Model of Affect Processing. Manual. Fribourg: Department of psychology, University of Fribourg.

Ricard, M., Cossette, L., \& Gouin Décarie, T. (1999). Développement social et affectif. In J. A. Ronda, \& E. Esperet (Eds.), Manuel de psychologie de l'enfant (pp. 215-231). Bruxelles: Editions Mardaga.

Rodas, N. V., Chavira, D. A., \& Baker, B. L. (2017). Emotion Socialization and Internalizing Behavior Problems in Diverse Youth: A Bidirectional Relationship across Childhood. Research in Developmental Disabilities, 62, 15-25.

https://doi.org/10.1016/j.ridd.2017.01.010

Rodas, N. V., Zeedyk, S. M., \& Baker, B. L. (2016). Unsupportive Parenting and Internalising Behaviour Problems in Children with or without Intellectual Disability. Journal of Intellectual Disability Research, 60, 1200-1211. https://doi.org/10.1111/jir.12332

Rogers, M. L., Halberstadt, A. G., Castro, V. L., MacCormack, J. K., \& Garrett-Peters, P. (2016). Maternal Emotion Socialization Differentially Predicts Third-Grade Children's Emotion Regulation and Lability. Emotion, 16, 280-291.

https://doi.org/10.1037/emo0000142

Ruffman, T., Slade, L., \& Crowe, E. (2002). The Relation between Children's and Mothers' Mental State Language and Theory of Mind Understanding. Child Development, 73, 734-751. https://doi.org/10.1111/1467-8624.00435

Shields, A., \& Cicchetti, D. (1997). Emotion Regulation among School-Age Children: The Development and Validation of a New Criterion Q-Sort Scale. Developmental Psychology, 33, 906-916. https://doi.org/10.1037/0012-1649.33.6.906

Slaughter, V., Peterson, C. C., \& Mackintosh, E. (2007). Mind What Mother Says: Narrative Input and Theory of Mind in Typical Children and Those on the Autism Spectrum. Child Development, 78, 839-858. https://doi.org/10.1111/j.1467-8624.2007.01036.x

Stevenson, M., \& Crnic, K. A. (2013). Intrusive Fathering, Children's Self-Regulation and Social Skills: A Mediation Analysis. Journal of Intellectual Disability Research, 57, 500-512. https://doi.org/10.1111/j.1365-2788.2012.01549.x

Thirion-Marissiaux, A.-F., \& Nader-Grosbois, N. (2008a). Theory of mind "beliefs", developmental characteristics and social understanding in children and adolescents with intellectual disabilities. Research in Developmental Disabilities, 29(6), 547-566. https://doi.org/10.1016/j.ridd.2007.09.004

Thirion-Marissiaux, A.-F., \& Nader-Grosbois, N. (2008b). Theory of Mind "Emotion", Developmental Characteristics and Social Understanding in Children and Adolescents with Intellectual Disabilities. Research in Developmental Disabilities, 29, 414-430. https://doi.org/10.1016/j.ridd.2007.07.001

Thirion-Marissiaux, A.-F., \& Nader-Grosbois, N. (2008c). Theory of Mind and Socio-Affective Abilities in Disabled Children and Adolescents. European Journal of Disability Research, 2, 133-155. https://doi.org/10.1016/j.alter.2008.02.003 
Thompson, R. A. (1994). Emotion Regulation: A Theme in Search of Definition. Monographs of the Society for Research in Child Development, 59, 25-52. https://doi.org/10.2307/1166137

Tingley, E. C., Gleason, J. B., \& Hooshyar, N. (1994). Mothers' Lexicon of Internal State Words in Speech to Children with Down Syndrome and to Nonhandicapped Children at Mealtime. Journal of Communication Disorders, 27, 135-155. https://doi.org/10.1016/0021-9924(94)90038-8

Vygotsky, L. (1978). Interaction between Learning and Development. Readings on the Development of Children, 23, 34-41.

Wechsler, D. (2004). Echelle d'intelligence de Wechsler pour la période préscolaire et primaire (Vol. 3). Paris: Les éditions du Centre de Psychologie appliquée.

Whitman, T. L. (1990). Self-Regulation and Mental Retardation. American Journal on Mental Retardation, 94, 347-362.

Wieland, N., Green, S., Ellingsen, R., \& Baker, B. L. (2014). Parent-Child Problem Solving in Families of Children with or without Intellectual Disability. Journal of Intellectual Disability Research, 58, 17-30. https://doi.org/10.1111/jir.12009

Wimmer, H., \& Perner, J. (1983). Beliefs about Beliefs: Representation and Constraining Function of Wrong Beliefs in Young Children's Understanding of Deception. Cognition, 13, 103-128. https://doi.org/10.1016/0010-0277(83)90004-5

Yeates, K. O., Bigler, E. D., Dennis, M., Gerhardt, C. A., Rubin, K. H., Stancin, T., \& Vannatta, K. (2007). Social Outcomes in Childhood Brain Disorder: A Heuristic Integration of Social Neuroscience and Developmental Psychology. Psychological Bulletin, 133, 535-556. https://doi.org/10.1037/0033-2909.133.3.535 